\title{
RESEARCH PROGRAMME ON SEISMIC PERFORMANCE OF REINFORCED CONCRETE WALLS: KEY RECOMMENDATIONS
}

\author{
Alex V. Shegay ${ }^{1}$, Farhad Dashti ${ }^{2}$, Lucas Hogan ${ }^{3}$, Yiqiu Lu ${ }^{4}$, \\ Arsalan Niroomandi ${ }^{5}$, Pouya Seifi ${ }^{6}$, Tongyue Zhang ${ }^{7}$, \\ Rajesh P. Dhakal ${ }^{8}$, Kenneth J. Elwood', \\ Richard S. Henry ${ }^{10}$ and Stefano Pampanin ${ }^{11}$
}

(Submitted September 2019; Reviewed December 2019; Accepted February 2020)

\begin{abstract}
A wide range of reinforced concrete (RC) wall performance was observed following the 2010/2011 Canterbury earthquakes, with most walls performing as expected, but some exhibiting undesirable and unexpected damage and failure characteristics. A comprehensive research programme, funded by the Building Performance Branch of the New Zealand Ministry of Business, Innovation and Employment, and involving both numerical and experimental studies, was developed to investigate the unexpected damage observed in the earthquakes and provide recommendations for the design and assessment procedures for RC walls. In particular, the studies focused on the performance of lightly reinforced walls; precast walls and connections; ductile walls; walls subjected to bi-directional loading; and walls prone to out-of-plane instability. This paper summarises each research programme and provides practical recommendations for the design and assessment of RC walls based on key findings, including recommended changes to NZS 3101 and the NZ Seismic Assessment Guidelines.
\end{abstract}

\section{INTRODUCTION}

Observations following the 2010/2011 Canterbury earthquakes indicated that the majority of reinforced concrete (RC) buildings performed as expected, with structural components developing the intended inelastic mechanism and damage characteristics. For RC walls, a wide range of performance was observed and reported in several reconnaissance reports and publications [1-4]. Most RC walls performed well, exhibiting the expected damage characteristics of distributed cracking and concrete cover spalling as shown in Figure 1a-c. In some cases, undesirable and unexpected damage characteristics of both old (pre-1982) and modern (post-1982) RC walls were observed, as summarised in Table 1 and illustrated in Figure 1d-n. While for modern walls, capacity design procedures prevented shear failures, other shortcomings were observed including damage to the central portion of the wall (Figure 1d-f) and end-region (Figure 1g-h); out-of-plane instability (Figure 1i); axial crushing (Figure 1j-k); localized reinforcement rupture (Figure 11) and inadequate reinforcement detailing (Figure 1m-n). While most of the observed failures did not induce collapse, it is likely that collapse could have initiated in some cases under higher intensity or longer duration shaking. Understanding the observed damage of walls designed to 'modern' standards (i.e., NZS 3101:1982 [5] NZS 3101:1995 [6] and NZS 3101:2006 [7]) was of particularly high priority to ensure necessary corrections and improvements were implemented as quickly as possible for the design of new buildings.

Shortly after the Canterbury earthquakes, several recommendations were published in the Structural Engineering Society of New Zealand Interim Design Guidance (SESOC) [8] and Canterbury Earthquakes Royal Commission (CERC) reports $[4,9]$ outlining recommended changes to design and construction practice to prevent the observed undesirable RC wall failures from occurring in the future. Many of these recommendations were broad in their scope, highlighting design deficiencies and areas requiring urgent consideration, without actually providing specific solutions. This was partially because the recommendations were largely based on professional judgement given the limited available research at the national and international level. The Building Performance Branch of the New Zealand Ministry of Business, Innovation and Employment (MBIE) issued a grant to undertake urgent research into the seismic performance of $\mathrm{RC}$ walls in order to investigate and develop the proposed CERC and SESOC recommendations into practical solutions that can be readily implemented into future amendments to NZS 3101 and the New Zealand Seismic Assessment Guideline for Existing Buildings [10] (hereafter referred to as the NZ Seismic Assessment Guideline). The funded studies focused on the performance of lightly reinforced walls; precast walls and connections; ductile

\footnotetext{
1 Corresponding Author, Research Fellow, Department of Architecture and Building Science, Tohoku University, Japan ashegay@ rcl.archi.tohoku.ac.jp

2 Research Associate, Quake Centre, University of Canterbury, New Zealand farhad.dashti@ canterbury.ac.nz

Lecturer, Department of Civil and Environmental Engineering, University of Auckland, New Zealand lucas.hogan@auckland.ac.nz

Postdoctoral Researcher, Department of Civil and Environmental Engineering, University of Auckland, New Zealand ylu765@aucklanduni.ac.nz

Structural Engineer, WSP Opus, Christchurch, New Zealand Arsalan.niroomandi@wsp.com

6 Structural engineer,WSP-Opus, Hamilton,New Zealand. Pouya.Seifi@wsp.com

Structural Engineer, Blue Barn Consulting, Auckland, New Zealand. tongyue.zhang@bluebarn.co.nz

${ }^{8}$ Professor, Department of Civil and Natural Resources Engineering, University of Canterbury, New Zealand rajesh.dhakal@ canterbury.ac.nz (Fellow)

9 Professor, Department of Civil and Environmental Engineering, University of Auckland, New Zealand k.elwood@auckland.ac.nz (Member)

${ }^{10}$ Senior Lecturer, Department of Civil and Environmental Engineering, University of Auckland, New Zealand rs.henry@auckland.ac.nz (Member)

${ }^{11}$ Professor, Department of Structural and Geotechnical Engineering, Sapienza University of Rome, Italy. Adjunct Professor, Department of Civil and Natural Resources Engineering, University of Canterbury, New Zealand stefano.pampanin@canterbury.ac.nz(Fellow)
} 
walls; walls subjected to bi-directional loading; and walls prone to out-of-plane instability.

Detailed findings of the research programme have been published elsewhere [11-41]; the objective of this paper is instead to assemble the key findings and practical recommendations for design practice. First, the organizational structure of the MBIE wall projects is presented, along with a brief review of each project's objectives and methodology. Second, the key findings and recommendations from each project are summarised, as they pertain to the design of new buildings and the assessment of existing buildings. The status of recommended changes for design provisions of NZS 3101 or NZ Seismic Assessment Guideline [10] is also highlighted.

\section{THE MBIE WALL PROJECTS}

In 2015, MBIE funded a three-year long research programme, managed by the UC Quake Centre, to identify the shortcomings in construction and design that led to the unexpected damage and failure modes of RC walls (summarised in Table 1 and shown in Figure 1) and provide recommendations for changes to guidelines and standards. Four overarching topics were identified as priority areas to address the objectives of the research programme: (i) performance of lightly reinforced and precast walls, (ii) performance of ductile walls, (iii) global outof-plane instability of walls and (iv) bi-directional loading effects on walls. A brief summary of objectives within each study and the methodology employed to achieve them is provided in Table 2-Table 5 below.

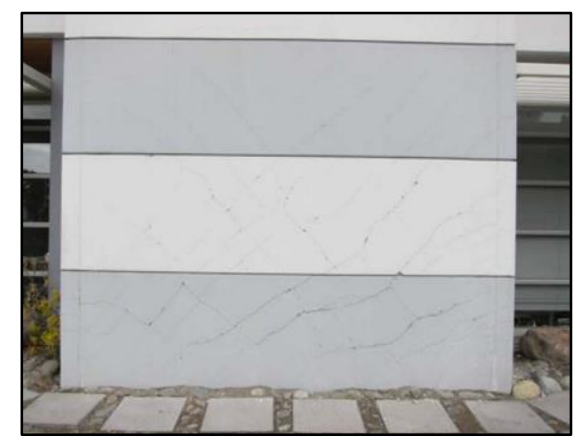

(a) Well-distributed cracking; NZ Statistics House (1999-2000)

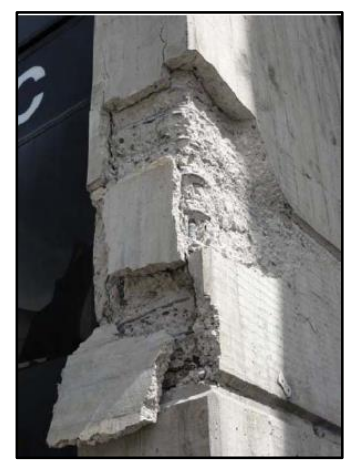

(c) Spalling of cover concrete; Crowne Plaza Hotel (1980-1989)
Table 1: Undesirable damage characteristics and failure modes observed in the 2010/2011 Canterbury earthquakes.

\begin{tabular}{|c|c|}
\hline Observed Damage & Figure \\
\hline $\begin{array}{l}\text { Concrete crushing in wall web } \\
\text { region }\end{array}$ & Figure 1d-f \\
\hline $\begin{array}{l}\text { Concrete crushing in wall end } \\
\text { region }\end{array}$ & Figure $1 g-h$ \\
\hline $\begin{array}{l}\text { Longitudinal reinforcement buckling } \\
\text { in end and web region }\end{array}$ & Figure $1 d-h, 1$ \\
\hline Out-of-plane wall instability & Figure $1 \mathrm{i}$ \\
\hline Out-of-plane shear-axial failure & Figure $1 i-j$ \\
\hline Axial crushing along the wall & Figure 1i-k \\
\hline $\begin{array}{l}\text { Rupture of longitudinal } \\
\text { reinforcement due to limited crack } \\
\text { distribution }\end{array}$ & Figure 11 \\
\hline $\begin{array}{l}\text { Loss of anchorage in } \\
\text { horizontal/shear reinforcement }\end{array}$ & Figure $1 \mathrm{~m}$ \\
\hline $\begin{array}{l}\text { Failure of spliced grouted ducts in } \\
\text { precast panels }\end{array}$ & Figure $1 \mathrm{n}$ \\
\hline
\end{tabular}

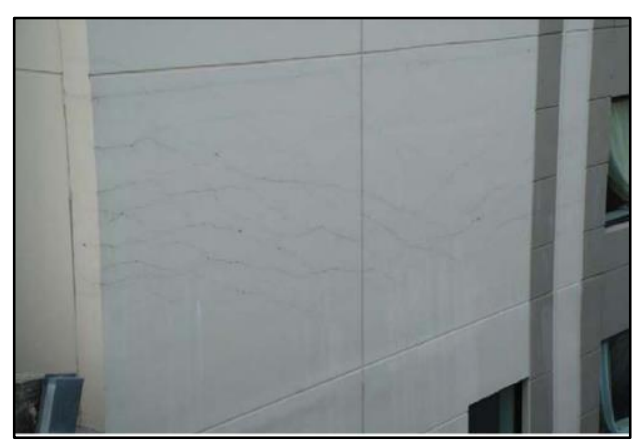

(b) Well-distributed cracking; Novotel building (2008-2009) [42]

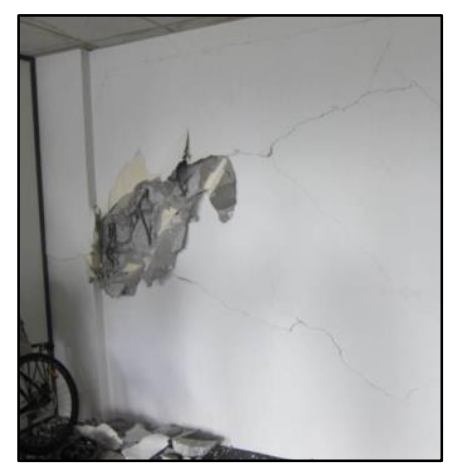

(d) Concrete spalling at web to boundary element interface; BNZ Tower (1967) [43]

Figure 1: RC wall damage characteristics and failure modes observed in the 2010/2011 Canterbury earthquakes (construction date provided in parenthesis). 


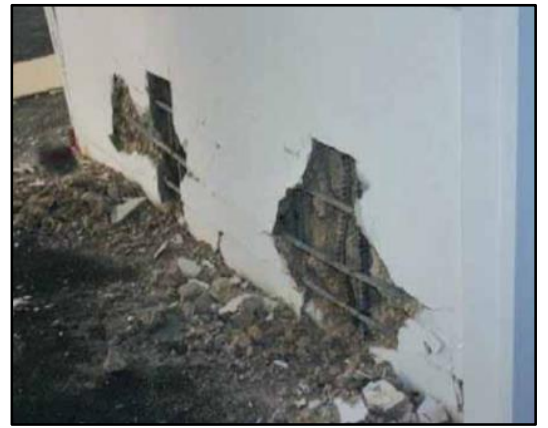

(e) Longitudinal reinforcement buckling; Canterbury Centre/Westpac Tower (1981) (source: Spencer Holmes)

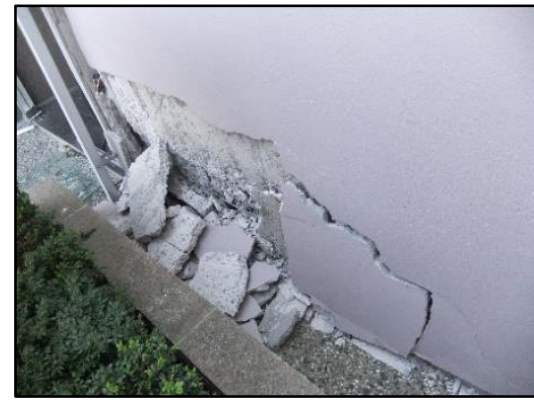

(g) End region core crushing; Terrace on the Park (2000-2010)

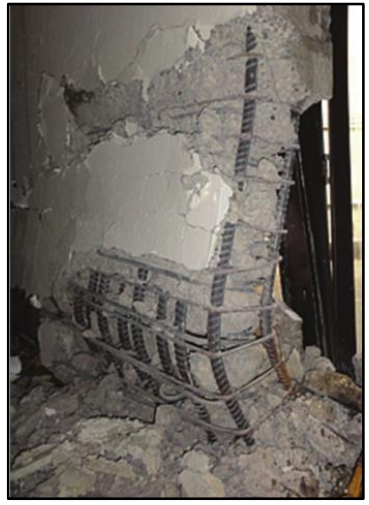

(i) Out-of-plane movement and instability of wall; 123 Victoria St (1980-1989)

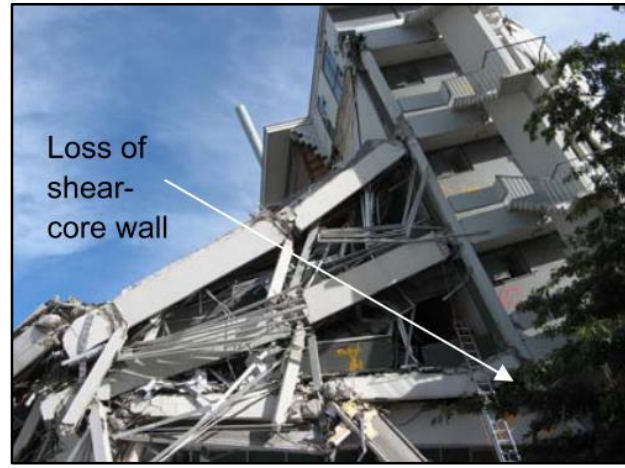

(k) Collapse likely initiated by axial failure of core wall [45]; PGC Building (1966)

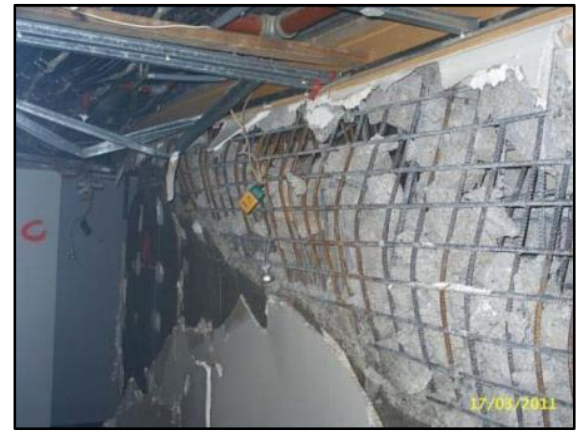

(f) Diagonal crushing of web concrete region; Terrace on the Park (2000-2010)

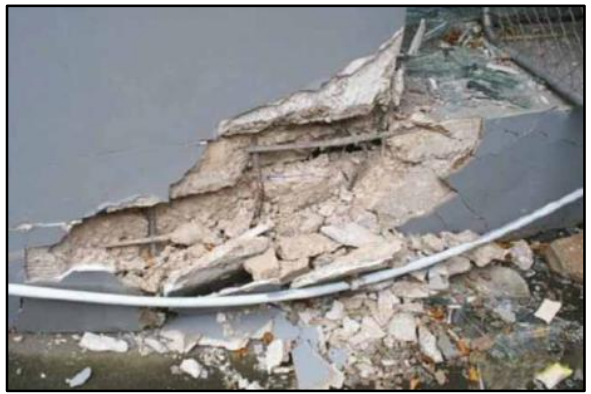

(h) End region core crushing and reinforcement buckling; AMI Building (1970-1979) [44]

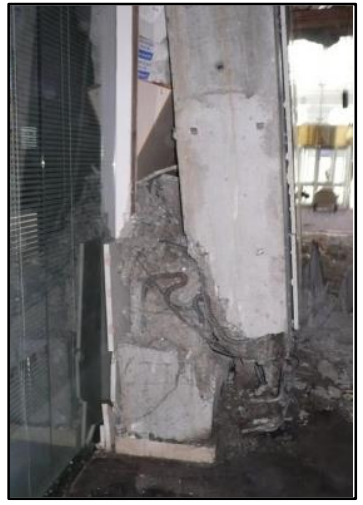

(j) Shear-axial failure of wall; Hotel Grand Chancellor (1985-1988)
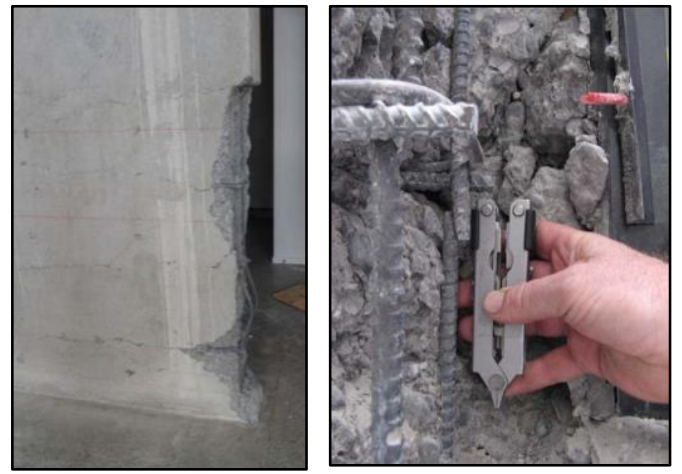

(1) Localized longitudinal reinforcement buckling and tensile fracture; Gallery Apartments, (20052007) 


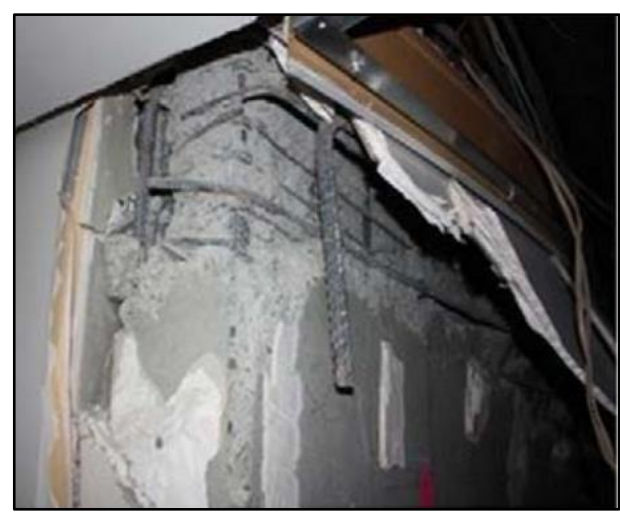

(m) Loss of horizontal reinforcement anchorage after cover spalling; Terrace on the Park (2000-2010)

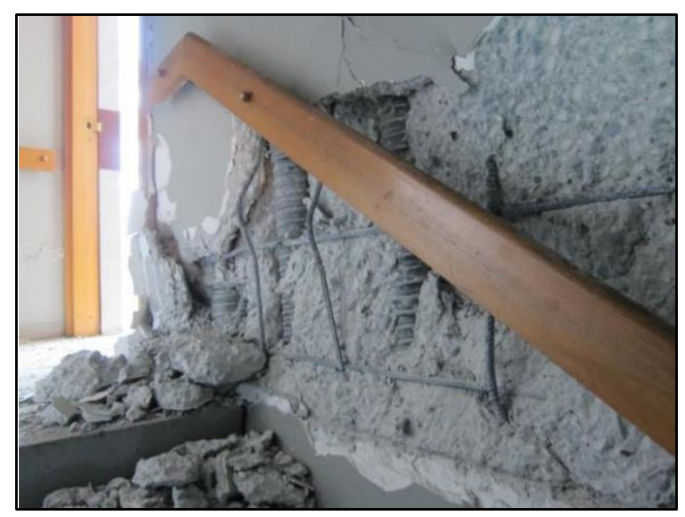

(n) Buckling of longitudinal reinforcement and spalling revealing grouted duct splice connection in precast wall; Crowne Plaza Hotel (1980-1989) [44]

Figure 1 (cont.): RC wall damage characteristics and failure modes observed in the 2010/2011 Canterbury earthquakes (construction date provided in parenthesis).

Table 2: Lightly reinforced and precast walls project aims and methodology.

\begin{tabular}{|l|l|l|}
\hline Aim & Methodology & Ref. \\
\hline $\begin{array}{l}\text { Assess the suitability of existing minimum } \\
\text { longitudinal reinforcement criteria, } \rho_{n}, \text { in } \\
\text { NZS 3101:2006-A2. }\end{array}$ & $\begin{array}{l}\text { Phase 1, testing of six walls with minimum longitudinal } \\
\text { reinforcement criteria considering different shear span ratios, axial } \\
\text { loads, and transverse reinforcement detailing. } \\
\text { Numerical modelling of walls to investigate a wider range of } \\
\text { design parameters and to compare requirements in different design } \\
\text { standards. }\end{array}$ & [28, 30, 38] \\
\hline $\begin{array}{l}\text { Recommend improvements to minimum } \\
\text { longitudinal feinforcement criteria for } \\
\text { NZS 3101:2006-A3 [46]. }\end{array}$ & $\begin{array}{l}\text { Development of expressions to estimate vertical reinforcement } \\
\text { required to achieve a range of ductility requirements. } \\
\text { Phase 2 testing of four walls to investigate the recommended } \\
\text { changes to minimum longitudinal reinforcement criteria. }\end{array}$ & [31-33] \\
\hline $\begin{array}{l}\text { Investigate the performance of dowel type } \\
\text { panel-to-foundation connections in low-rise } \\
\text { precast buildings. }\end{array}$ & $\begin{array}{l}\text { Experimental programme consisting of 12 out-of-plane panel tests } \\
\text { using existing connection detailing, 15 out-of-plane panel tests } \\
\text { using alternative connection detailing, 3 in-plane panel tests, and } \\
\text { two bi-directional panel tests of key connection details. }\end{array}$ & [34] \\
\hline $\begin{array}{l}\text { Investigate the performance of grouted panel } \\
\text { connections in precast buildings and transverse } \\
\text { reinforcement detailing recommended in } \\
\text { SESOC interim design guidelines. }\end{array}$ & $\begin{array}{l}\text { Seven in-plane tests on precast walls with grouted Drossbach duct } \\
\text { connections including different geometry, axial load and } \\
\text { transverse reinforcement detailing. } \\
\text { Two in-plane tests on precast walls with grout sleeve connections. }\end{array}$ & {$[36,37]$} \\
\hline $\begin{array}{l}\text { Investigate axial failure of singly reinforced } \\
\text { walls in existing buildings. }\end{array}$ & $\begin{array}{l}\text { Four in-plane wall tests on singly reinforced walls with typical } \\
\text { 1960s detailing. }\end{array}$ & [23,35] \\
\hline
\end{tabular}


Table 3: Ductile wall project aims and methodology.

\begin{tabular}{|l|l|l|}
\hline Aim & Methodology & Ref. \\
\hline $\begin{array}{l}\text { To investigate the appropriateness of 30\% axial } \\
\text { load ratio limit introduced to NZS 3101:2006- } \\
\text { A3 with respect to wall ductility. }\end{array}$ & $\begin{array}{l}\text { Testing of four RC walls designed with ductile detailing and } \\
\text { subjected to a range of axial load ratios. }\end{array}$ & {$[11,12]$} \\
\hline $\begin{array}{l}\text { Assess effect of end region and web region } \\
\text { reinforcement detailing on wall ductility. }\end{array}$ & $\begin{array}{l}\text { Variation of hoops, cross-ties, end region confinement length and } \\
\text { inclusion of ties in the web region of the wall in the above-noted } \\
\text { four RC wall tests. }\end{array}$ & {$[11,12]$} \\
\hline $\begin{array}{l}\text { Investigate the suitability of wall deformation } \\
\text { demand and capacity limits with respect to } \\
\text { reinforcement detailing and loading demands. }\end{array}$ & $\begin{array}{l}\text { Empirical study on the wall deformation capacity using a database } \\
\text { of ductile walls previously tested in the literature. }\end{array}$ & {$[12,16]$} \\
\hline
\end{tabular}

Table 4: Global out-of-plane instability/buckling of walls project aims and methodology.

\begin{tabular}{|c|c|c|}
\hline Aim & Methodology & Ref. \\
\hline $\begin{array}{l}\text { Gain an in-depth understanding of the global } \\
\text { out-of-plane instability/buckling mechanism, } \\
\text { including the effect of governing parameters } \\
\text { such as wall section thickness, length, axial } \\
\text { load and longitudinal reinforcement ratio. }\end{array}$ & $\begin{array}{l}\text { A numerical study to develop a modelling approach capable of } \\
\text { capturing different failure modes of structural walls including the } \\
\text { global out-of-plane instability/buckling mechanism. } \\
\text { A numerical parametric study on the out-of-plane response of } \\
\text { singly and doubly reinforced concrete walls using the verified } \\
\text { modelling approach to link the effects of the key wall parameters } \\
\text { with progression of out-of-plane instability. }\end{array}$ & $\begin{array}{r}{[13-15} \\
17-19 \\
39-41]\end{array}$ \\
\hline $\begin{array}{l}\text { Verify the theory of the out-of-plane instability } \\
\text { mechanism through experimental testing. }\end{array}$ & $\begin{array}{l}\text { Experimental testing of four slender rectangular walls ranging in } \\
\text { thickness, length and axial load and comparison of the } \\
\text { observations with the FEM predictions. }\end{array}$ & $\begin{array}{r}{[14,15} \\
40]\end{array}$ \\
\hline $\begin{array}{l}\text { Verify existing analytical models for the global } \\
\text { out-of-plane instability/buckling mechanism } \\
\text { and evaluate the suitability of the existing } \\
\text { requirements in NZS 3101:2006-A3 [46] for } \\
\text { prevention of out-of-plane instability. }\end{array}$ & $\begin{array}{l}\text { Comparison of wall instability observed in earthquakes and } \\
\text { experimental testing (including the above-noted four RC wall } \\
\text { tests) with existing theoretical and analytical models. }\end{array}$ & $\begin{array}{r}{[20,22,} \\
39-41]\end{array}$ \\
\hline
\end{tabular}

Table 5: Response of walls to bi-directional loading aims and methodology.

\begin{tabular}{|c|c|c|}
\hline Aim & Methodology & Ref. \\
\hline $\begin{array}{l}\text { Investigate the effects of bi-directional loading } \\
\text { on the behaviour, performance and failure } \\
\text { modes of RC walls when compared to typical } \\
\text { performance under in-plane loading only. }\end{array}$ & $\begin{array}{l}\text { Experimental quasi-static cyclic testing of three walls under uni- } \\
\text { and bi-directional loading. } \\
\text { Numerical parametric investigation on walls prone to shear-axial } \\
\text { failure subjected to uni- and bi-directional loading. }\end{array}$ & {$[25,26]$} \\
\hline $\begin{array}{l}\text { Assess the effects of lateral loading pattern on } \\
\text { the seismic behaviour of rectangular RC walls. }\end{array}$ & $\begin{array}{l}\text { Experimental investigation on the effects of three different lateral } \\
\text { loading patterns, i.e. clover leaf and skewed loading with } 45^{\circ} \text { and } \\
85^{\circ} \text { with respect to the in-plane axis. } \\
\text { Numerical investigation on the effects of lateral skewed loading } \\
\text { angle on walls prone to shear-axial failure. }\end{array}$ & {$[25,26]$} \\
\hline $\begin{array}{l}\text { Develop a better understanding of Grand } \\
\text { Chancellor Hotel's Wall D5-6 failure and walls } \\
\text { subjected to bi-directional loading by } \\
\text { identifying key parameters that control this } \\
\text { failure mode. Use these parameters to develop } \\
\text { an analytical method suitable for wall design } \\
\text { and assessment purposes. }\end{array}$ & $\begin{array}{l}\text { Numerical modelling of Grand Chancellor Hotel wall (Figure 1j). } \\
\text { Testing of three walls under skew loading conditions with } \\
\text { varying end region reinforcement detailing. } \\
\text { Numerical parametric investigation on walls subjected to bi- } \\
\text { directional loading. }\end{array}$ & $\begin{array}{r}{[26,27,} \\
29]\end{array}$ \\
\hline
\end{tabular}




\section{KEY FINDINGS RELEVANT TO NEW DESIGN}

Over the course of the four projects described above, several findings were obtained with respect to the design of new RC walls. The key findings and corresponding recommendations are summarised below. External references with further details on the summarised studies are also provided.

\section{Minimum Vertical Reinforcement}

Cyclic, quasi-static testing of six lightly reinforced walls in the first experimental phase [38] demonstrated that the response of walls with minimum total vertical reinforcement ratio $\left(\rho_{\mathrm{n}}\right)$ as prescribed in NZS 3101:2006-A2, as per Equation (1), was dominated by one to three wide cracks as shown in Figure $2 \mathrm{a}$.

$$
\rho_{n} \geq \frac{\sqrt{f_{c}^{\prime}}}{4 f_{y}}
$$

where $f_{c}^{\prime}=$ design concrete compressive strength (MPa); and $f_{y}=$ nominal longitudinal reinforcement yield strength (MPa).

Cracks were not uniformly distributed over the NZS 3101assumed plastic hinge length (defined as the smaller of 0.5 times the wall length or $0.13 \mathrm{M} / \mathrm{V}$, where $\mathrm{M} / \mathrm{V}$ is the ultimate wall base moment to base shear ratio), with large concentrations in the measured curvature profile at the crack locations. Concentrated strain demands at the locations of the discrete cracks resulted in buckling and eventual rupture of the longitudinal reinforcement, leading to loss of lateral-load carrying capacity. Variation in shear span ratio, transverse reinforcement ratio and axial load did not affect this damage pattern. Numerical modelling of full-scale lightly reinforced walls [28] showed that the discrete cracking pattern was similar to the scaled wall tests. Due to a larger wall length in full-scale walls, for any given wall rotation larger strains are induced at the crack locations compared with the scaled test walls, as explained in Lu et al. [38]. Consequently, full-scaled walls will have a reduced plastic rotation capacity and, by association, a reduced interstorey drift capacity. Based on these observations, it was concluded that the drift capacity observed for the test walls may overestimate the probable drift capacity of full-scale walls.

The second experimental phase [32] investigated the proposed minimum vertical reinforcement limits shown graphically in Figure 3 (based on formation of secondary cracks [33]), with the reinforcement ratio in the end region of the test walls varying above and below the proposed limit. In all cases, a welldistributed crack pattern formed up the height of the wall as shown Figure $2 b$, with smaller crack spacing and narrower width compared to walls conforming to Equation (1) tested in the first phase. Reinforcement ratios above the proposed limits in Figure 3 were shown not to produce a significant improvement in wall performance.

Key recommendation: The minimum distributed vertical reinforcement criterion of NZS 3101:2006-A2 (Equation (1)) is not adequate to ensure the formation of a distributed crack pattern and uniform curvature distribution over the assumed wall plastic hinge length. However, the same minimum distributed vertical reinforcement is sufficient to achieve deformation capacity for nominally ductile plastic regions.

Key recommendation: Increase the minimum longitudinal reinforcement limit in the end regions of wall as shown in Figure 3 to achieve the desired distributed crack pattern in the wall plastic hinge. This change has been adopted in NZS 3101:2006-A3 for limited ductile and ductile walls.

Future research: The proposed minimum reinforcement limits should be validated against wall types outside the scope of this study, such as tall walls, non-rectangular walls and core walls.

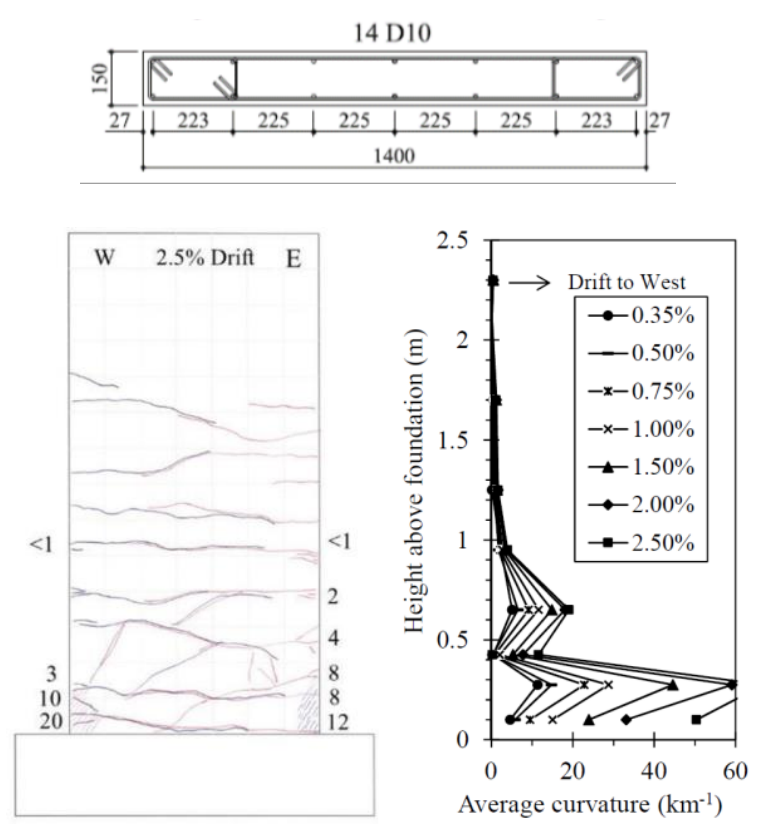

(a)
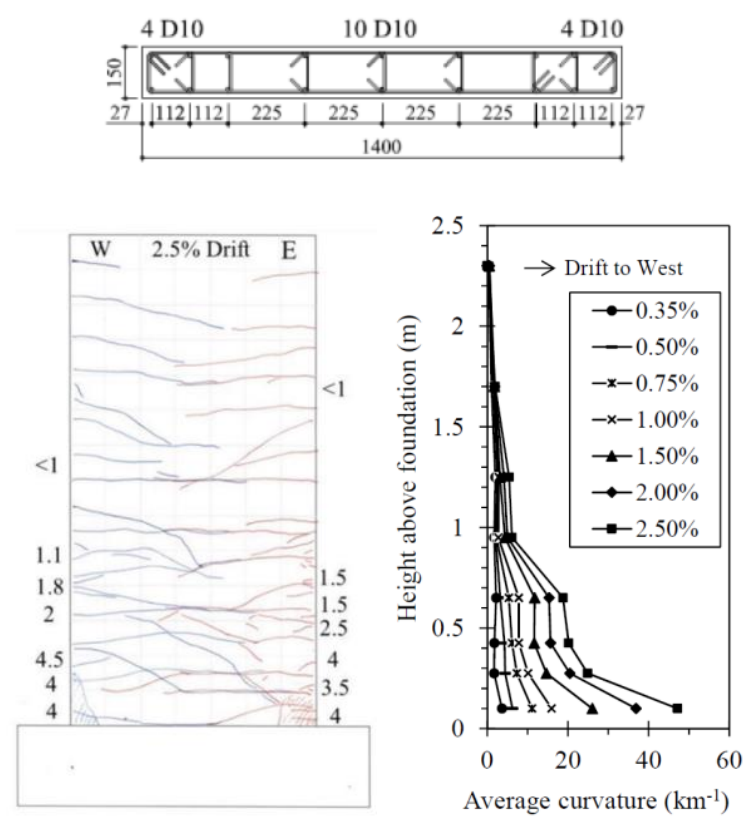

(b)

Figure 2: Curvature, crack distribution and maximum crack widths at $2.5 \%$ drift peak of lightly reinforced wall designed to (a) superseded minimum longitudinal reinforcement requirements in NZS 3101:2006-A2 and (b) new minimum longitudinal reinforcement requirements in NZS 3101:2006-A3. 


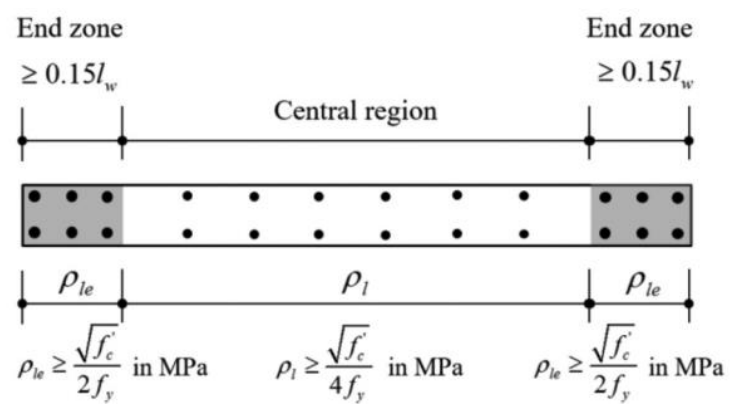

\section{Figure 3: Minimum longitudinal reinforcement criteria adopted in NZS 3101:2006-A3.}

\section{Dowel Connections in Low-rise Precast Walls}

Out-of-plane, quasi-static testing of the commonly-used dowel type precast panel-to-foundation connections with shallow embedded inserts, as shown in Figure $4 \mathrm{a}$, demonstrated that failure occurs in the connection when the panel flexural crack extends behind the insert (as indicated by the red line in the figure) to cause a breakout failure mode [34]. Due to the connection failure, the full out-of-plane nominal flexural capacity of the precast wall could not be developed. In addition, existing methods used to calculate the strength of the threaded insert as an anchor (Ch. 17 of NZS 3101) are not appropriate to estimate the strength of dowel connections with threaded inserts [34]. Bi-directional, quasi-static testing [34] further emphasised the deficiencies of the shallow embedded inserts with the joint opening due to out-of-plane loading, leading to cracking and failure of the panel within the joint region during in-plane loading. Several alternative connection details were tested [34], including varying the insert embedment depth into the wall panel (Figure 4b), the use of conventional continuous starter bars through the joint (Figure 4c-d), and supplemental transverse reinforcement in the panel to bridge the conical failure plane (Figure 4e-f). It was determined that all of these alternative connection details showed improved performance when compared to the use of shallow embedded inserts [34]. However, as summarised by Hogan et al. [34], the use of doweltype connections in thin singly reinforcement precast panels are inefficient and prone to poor seismic performance. The use of increased panel thickness, double layer of reinforcement, or conventional grouted panel-to-foundation connections (such as that tested in [36]) is likely to substantially improve the seismic performance and robustness of panel-to-foundation connections in low-rise buildings.

Key recommendation: The use of dowel-type precast panelto-foundation connections with shallow embedded inserts (Figure 4a) should be avoided. The connection is not compliant with NZS 3101:2006 and results in a brittle failure at loads below the panel nominal flexural capacity. Existing methods used to estimate the anchorage capacity of the inserts are inappropriate for such connections.

Key recommendation: Although the alternative connection details showed improved performance during testing, there are inherent vulnerabilities when using dowel-type connections in combination with thin singly reinforced panels that cannot be avoided. If using dowel connections, it is recommended to use an increased panel thickness and double layer of reinforcement. Alternatively, a foundation directly below the panel using conventional grouted Drossbach connections is expected to provide a superior performance to dowel-type connections.

Future research: Recommended detailing for panel-tofoundation connections in low-rise buildings needs to be developed and tested that are compliant with NZS 3101, have robust load paths and design methods, and have been verified by large-scale testing. Such research is currently in progress and further guidance is expected in 2021.

Future research: Recommended retrofit solutions for the common connection in Figure 4a need to be developed and verified.

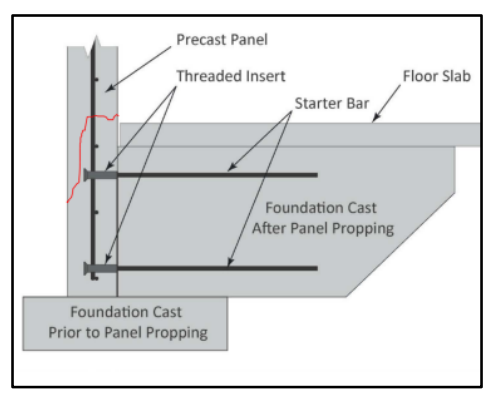

(a)

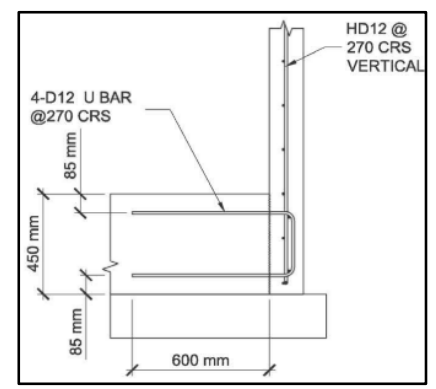

(d)

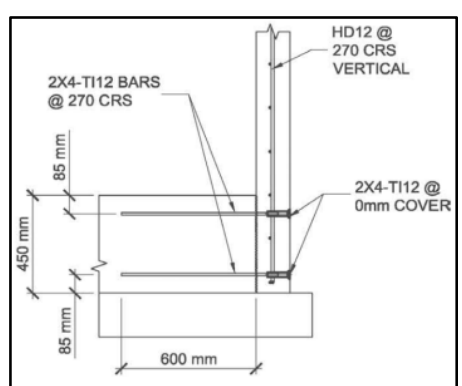

(b)

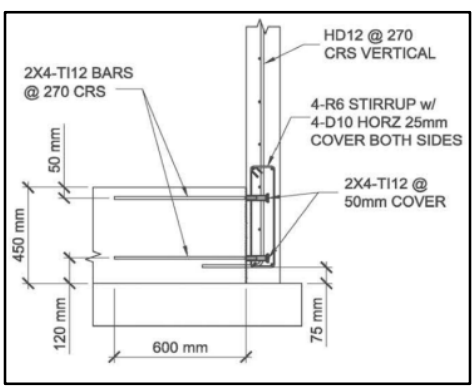

(e)

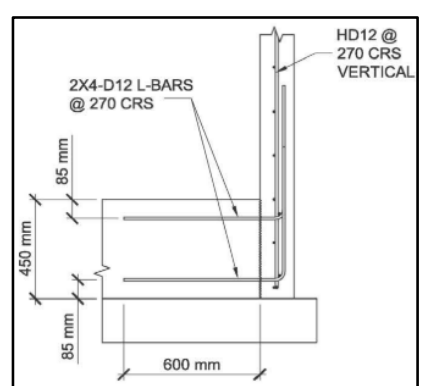

(c)

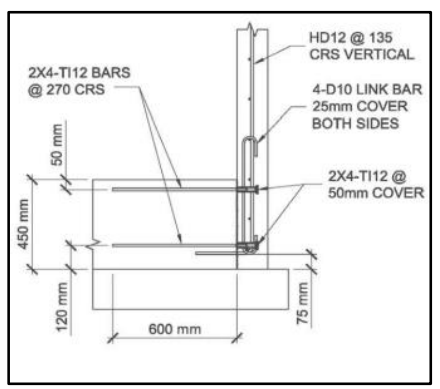

(f)

Figure 4: (a) Common detailing for precast wall-to-foundation connection with undesirable failure mode, (b-f) alternative improved connection detailing that can achieve full nominal moment capacity of precast wall. 


\section{Grouted Precast Wall-to-Foundation Connections}

Cyclic, pseudo-static testing of seven singly-reinforced precast walls with varying geometry, longitudinal reinforcement ratio and axial load showed that the grouted Drossbach duct precast wall-to-foundation connection, shown in Figure 5a, performed as expected when axial load demands are low [36]. With no axial load applied, the panel can achieve and exceed its full nominal moment and is governed by fracture of reinforcement at the wall-to-foundation interface. In cases where axial load ratio was increased to 5\% or the wall panel length was increased to $2 \mathrm{~m}$, the resulting increase in compression strain demands induced spalling in the wall end region, exposing metal ducts as shown in Figure $5 \mathrm{c}$. When the spalling of concrete neared the height of the metal duct, the failure mode of the panel changed from fracture of starter bars to pull-out of metal ducts from the wall. The use of transverse confinement reinforcement around ducts, as recommended by SESOC [8] were shown to minimize spalling, thus preserving the integrity of the duct to panel bond, as shown in Figure 5d. It is noted that by doing so, wall deformation becomes governed by rocking of the panel on a single base crack potentially leading to fracture of the longitudinal reinforcement.

Testing of two wall panels with proprietary grout sleeve wallto-foundation connections (shown in Figure 5b) [37] highlighted several potential vulnerabilities with the lateral load response not present in walls with grouted Drossbach ducts. Slip at the threaded end of the grout sleeve reduced the wall initial stiffness and thread failure was also observed during some grout sleeve tests. Pull out of reinforcement from the grouted end of the sleeve was observed during wall testing prior to the panel reaching nominal flexural capacity and was attributed to a combination of cyclic loading demands and poor grout quality. Individual grout sleeve tests highlighted the influence of construction quality, with grout voids resulting in pull-out of the reinforcement from the sleeve.

Key recommendation: Transverse confinement reinforcement should be placed around Drossbach ducts in order to provide a reliable and robust connection between precast panels and foundations, especially when compression demands are sufficient to initiate spalling of cover concrete.

Key recommendation: Proprietary grout sleeves should only be used if adequate test evidence is provided to ensure that they meet the requirements for mechanical connections in NZS 3101:2006.

Key recommendation: Typically grouted precast panel-tofoundation connections should only be used for nominally ductile walls unless tests and analysis can show that sufficient ductility can be achieved, particularly when considering potential fracture of connection reinforcement when using a jointed connection design approach.

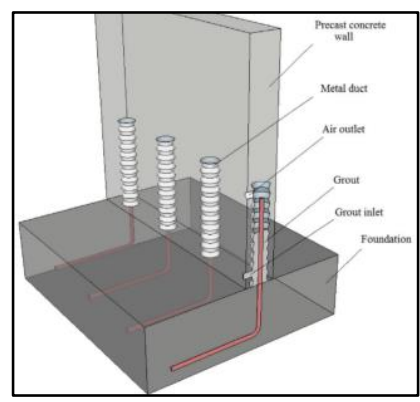

(a)

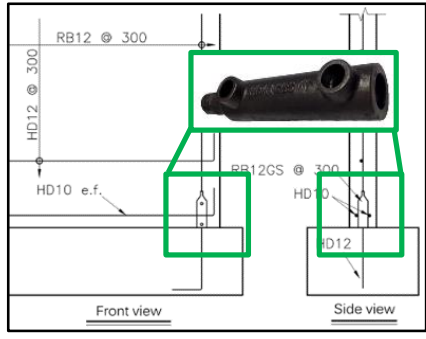

(b)

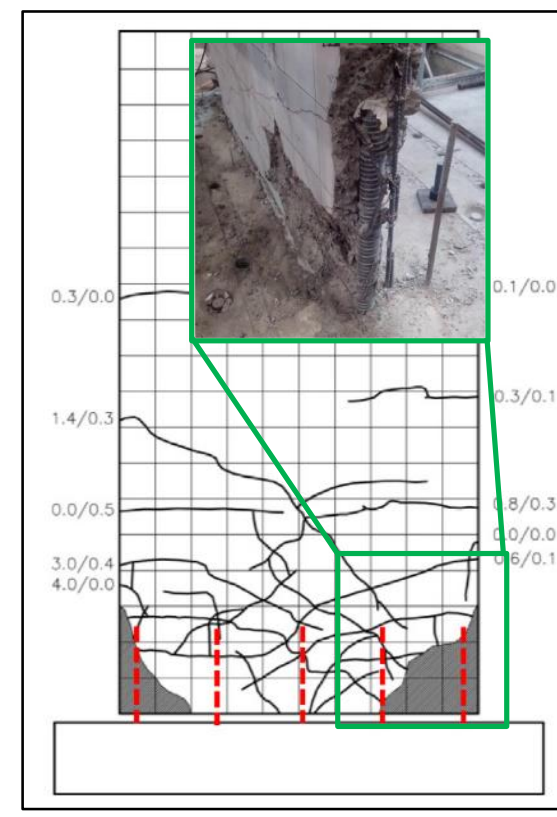

(c)

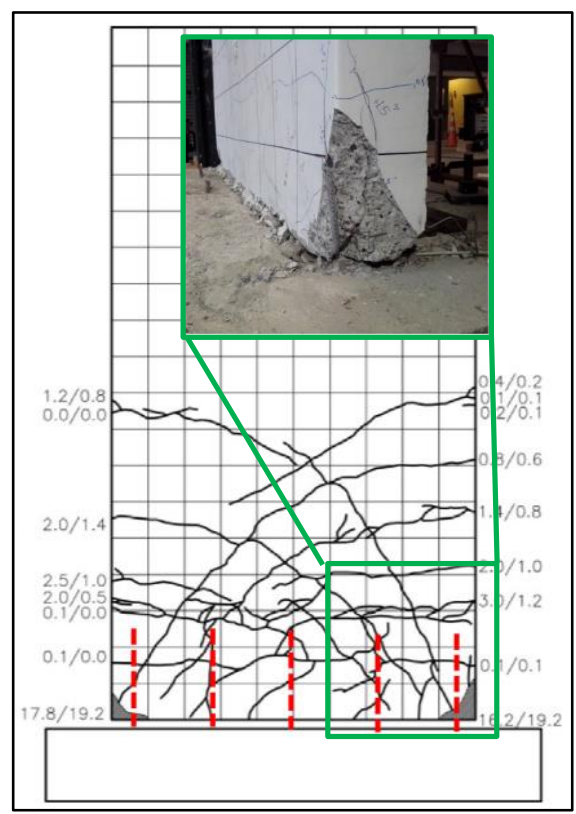

(d)

Figure 5: (a) Configuration of the Drossbach wall-to-foundation connection, (b) configuration of the grouted sleeve wall-tofoundation connection, (c) performance of Drossbach duct grouted connection without confinement around metal ducts and (d) with confinement provided around metal ducts.

\section{Design of Ductile Walls}

\section{Transverse Reinforcement Detailing}

Four RC walls, designed with ductile detailing and subjected to a range of axial load ratios, were tested under cyclic, quasistatic loading to assess drift capacity. Two of the four tested walls had varied web and end region transverse reinforcement detailing as illustrated in Figure 6, including (i) inclusion/exclusion of cross-ties on longitudinal reinforcement in the wall web region, (ii) a varied confined length with respect to the neutral axis length and (iii) use of only hoops versus only cross-ties to confine the wall end region. In testing, no immediate benefit was evident from the use of cross-ties in the web region or the use of a longer confinement length; however, previous experimental [47] and numerical [48] studies suggested that benefit can be gained from this detailing for walls subjected to high shear stress demands. The exact wall design and demand characteristics that trigger the necessity for this detailing were not investigated. Crushing of end regions confined only with hoops resulted in fracture of hoops legs while crushing of end regions confined only with cross-ties 
resulted in unbending of the $180^{\circ}$ cross-tie hooks as shown in Figure 7. Despite the difference in failure mode, no impact was observed on the global wall deformation capacity, indicating that equivalent global performance can be attained from hoops and $180^{\circ}$ cross-ties.

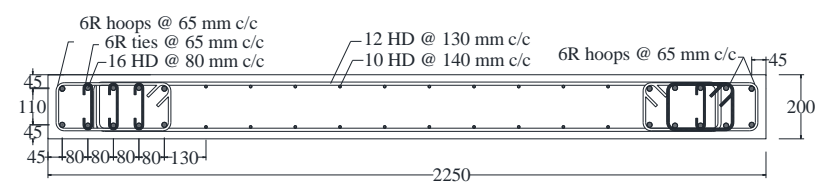

(a)

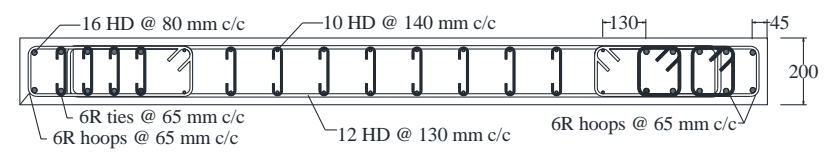

(b)

Figure 6: Cross-sections of walls with (a) confinement length shorter than neutral axis length and no cross-ties on web longitudinal reinforcement; (b) fully confined neutral axis length and cross-ties on web longitudinal reinforcement.

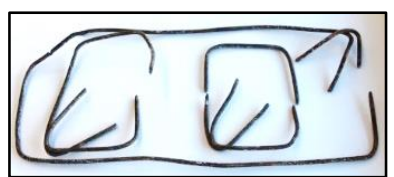

(a)

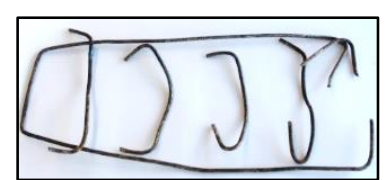

(b)
Figure 7: Damage to hoop and cross-tie confinement in the tested ductile walls [11].

\section{Axial Load Limits and Deformation Demand Limits}

Results of testing four ductile $\mathrm{RC}$ walls under increasing axial load ratio [11] combined with results from a database of previously tested walls in literature showed that deformation capacity (expressed as curvature ductility, $K_{d}$ ) was found to decrease with increasing axial load. For walls subjected to axial load ratios of $20 \%$ or higher, curvature ductility capacity was below 16, the deformation demand limit in NZS 3101:2006-A3 for ductile walls. Based on this, it was deemed that the axial load limit of 0.3 $\phi \mathrm{Agf}_{\mathrm{g}} \mathrm{c}$ introduced in NZS 3101:2006-A3 is too high for the allowable design deformation demands.

Factors in addition to axial load were identified to affect the curvature ductility capacity of ductile walls, including longitudinal reinforcement ratio, wall geometry and transverse reinforcement detailing in the wall end region. To differentiate between these parameters, the deformation capacity from a collected database of ductile walls (including the four walls tested in [11]) are plotted in Figure 8a against their neutral axis to wall length ratio, $c / L_{w}$, and sorted by the vertical spacing of transverse hoops to longitudinal bar diameter ratio, $s / d_{b}$. Typically, design deformation demand limits (such as the $K_{d}$ limits in NZS 3101:2006-A3) should be representative of the lower-bound capacity of experimental data. It can be seen in Figure 8a that this is not the case for the existing ductile wall deformation demand limits in NZS 3101:2006-A3. To better represent the lower-bound curvature ductility of the data, a curvature ductility demand limit was defined as a function of $c / L_{w}, s / d_{b}$ and a compression concrete strain limit, $\varepsilon_{c m}$, as shown in Equation (2). Recommended values to define deformation demand design limits for ductile and nominally/limited ductile walls are provided in Table 6. Full details of the derivation of Equation (2) are provided by Shegay et al. [16]. The proposed design deformation demand limits for ductile walls and nominally/limited ductile walls are plotted with experimental data in Figure 8a and Figure 8b, respectively. It is evident from both figures that the proposed limits are a more suitable representation of lower-bound capacity than the current limit in NZS 3101.

$$
K_{d}=\frac{\varepsilon_{c m}}{2 \varepsilon_{y}\left(\frac{c}{L_{w}}\right)} \leq K_{d \_ \text {max }}
$$

Key recommendation: It is recommended, as per NZS 3101:2006-A3, that longer confinement length and crossties on web longitudinal reinforcement be used to account for uncertainty in wall axial load and to account for diagonal compression struts that can develop outside the neutral axis zone in walls that are subjected to higher shear stress demands.

Key recommendation: Hoops and $180^{\circ}$ hooked cross-ties can be used interchangeably to confine wall end regions without compromising the global wall deformation capacity.

Key recommendation: The axial load ratio limit of $0.3 \phi \mathrm{Agf}^{\prime} \mathrm{c}$ in NZS 3101:2006-A3 is too high in relation to the NZS 3101:2006-A3 deformation demand limits.

Key recommendation: NZS 3101:2006-A3 curvature ductility demand limits for ductile walls are not representative of the range of ductile wall performance observed in experimental testing. It is recommended that deformation demand limits for design of RC walls be described by Equation (2), with reference to Table 6 .

Future research: Research needs to be conducted to validate the conditions in Cl. 11.4.5.3 of NZS 3101:2006-A3 that trigger the requirement for web cross-ties.

\section{Bi-Directional Loading}

\section{Damage Progression}

Three RC walls were tested to investigate the influence of bidirectional loading: a baseline in-plane test, a clover-leaf loading pattern, and $45^{\circ}$ skew loading $[25,26]$. Bi-directional loading and skew loading (uni-directional loading skewed from the principle axes) of conventional $\mathrm{RC}$ walls was shown to accelerate several wall damage states (e.g., concrete cover spalling, longitudinal reinforcement buckling) in the end region and web region of a wall when compared to in-plane loading $[25,26]$. Based on the experimental results, the in-plane drift capacity of the wall tested under a bi-directional clover-leaf loading protocol was reduced by $20 \%$ compared to the benchmark in-plane loading only. These observations highlight the necessity of providing cross-ties on longitudinal web reinforcement (which restrain reinforcement buckling and provide confinement to concrete) to reduce damage in the central portion of the wall under bi-directional loading demands. 


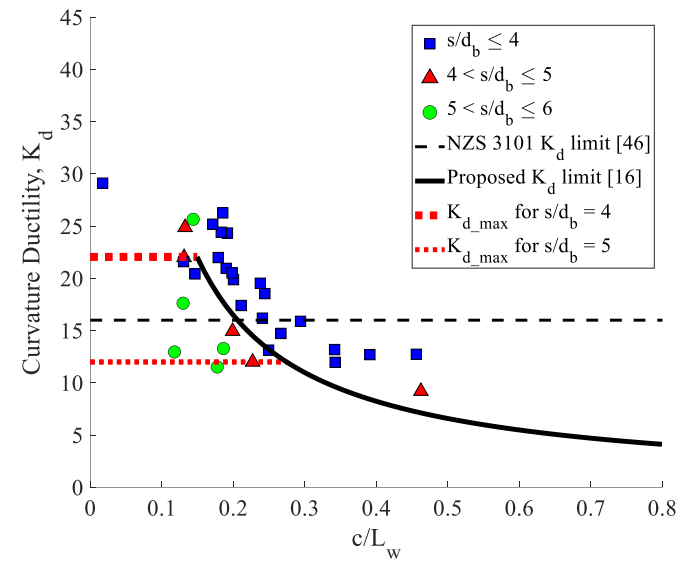

(a)

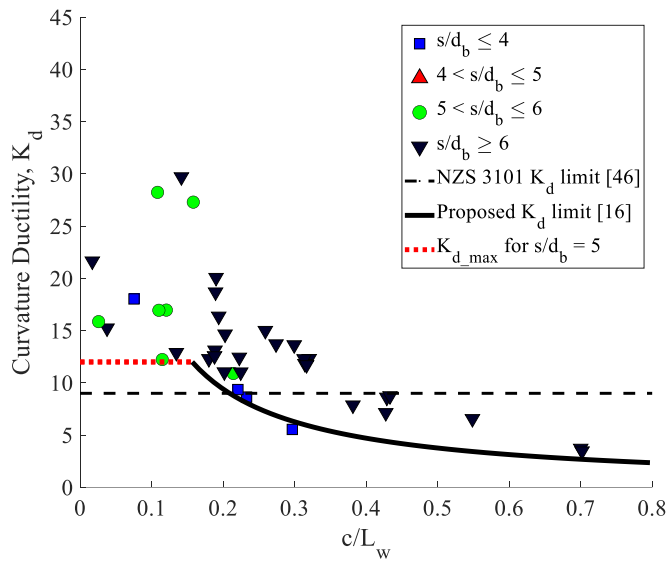

(b)

Figure 8: Curvature ductility capacity of ductile walls including the (a) existing NZS 3101:2006-A3 deformation demand limits, (b) proposed deformation demand limits.

Table 6: Concrete compressive strain limits and $K_{d \_m a x}$ limits for the proposed model in Equation (2).

\begin{tabular}{|c|c|c|c|c|}
\hline & \multicolumn{2}{|c|}{ Ductile walls } & \multicolumn{2}{c|}{ Nominally/Limited ductile walls } \\
\hline & Design & Assessment & Design & 0.012 \\
\hline$\varepsilon_{c m}$ & 0.014 & 0.018 & 0.008 & 12 \\
\hline$K_{d \_ \text {max }}$ & \multicolumn{2}{|c|}{$\begin{array}{l}12 \text { for } \mathrm{s} / \mathrm{d}_{\mathrm{b}} \geq 5^{*} \\
22 \text { for } \mathrm{s} / \mathrm{d}_{\mathrm{b}} \leq 4^{*}\end{array}$} & \multicolumn{2}{c|}{} \\
\hline
\end{tabular}

$*$ Linear interpolation for $4 \leq \mathrm{s} / \mathrm{d}_{\mathrm{b}} \leq 5$.

Assessment of Out-of-Plane Shear-Axial Failure in Bidirectionally Loaded Walls

The bi-directional displacement response of the Grand Chancellor Hotel building to the 22 February 2011 and 4 September 2010 Canterbury earthquakes was determined by superimposing two independent linear time-history analysis of an equivalent single degree of freedom system (one in each direction). The analysis suggested that the failure of Wall D5-6 (Figure 1j) occurred when the earthquake loading was strongly biased towards the out-of-plane direction of the wall [26, 27]. Based on results of cyclic, pseudo-static testing of three walls (with various section detailing and subjected to bi-directional loading) and results of numerical analysis (case study on Wall D5-6 from Grand Chancellor Hotel and numerical parametric study) $[26,27]$, it was found that bi-directional loading can reduce the capacity of an $\mathrm{RC}$ wall with a combined shear-axial $\left(\mathrm{V}_{\mathrm{x}}-\mathrm{V}_{\mathrm{y}}-\mathrm{N}\right)$ failure mechanism occurring earlier than when subjected to in-plane loads only. This effect is similar to the reduction in flexural capacity expected due to bi-directional loading of $\mathrm{RC}$ elements $\left(\mathrm{M}_{\mathrm{x}}-\mathrm{M}_{\mathrm{y}}-\mathrm{N}\right.$ interaction). This shearaxial failure mode involves the development of diagonal compression cracks in the out-of-plane direction (i.e., through the thickness of the wall) and almost along the entire length of the wall followed by sliding of the wall along this crack in the out-of-plane direction due to a combination of existing axial and induced out-of-plane load demands. An example of this failure mode is shown in Figure 9 and a detailed description of its development and evolution is provided in Niroomandi [26] The experimental and numerical campaign highlighted that while bi-directional loading is a key factor in the development of diagonal cracks through the thickness of the wall and the subsequent combined shear-axial failure, additional wall parameters such as (moderate-to-large) wall thickness, higher axial load ratio, lower sectional aspect ratio $\left(L_{w} / t_{w}\right)$ and lower transverse reinforcement ratio can also increase the likelihood of this failure mode.

Findings by Niroomandi [26] demonstrate that walls subject to bi-directional loading can experience a shear-axial failure described above with axial loads as low as $0.1 \mathrm{Agf}^{\prime} \mathrm{c}$ and for aspect ratios $L_{w} / t_{w} \leq 12$. For such walls, it is essential to fully confine the neutral axis length and to provide transverse reinforcement in the web in accordance with NZS 3101 for ductile and limited ductile walls.

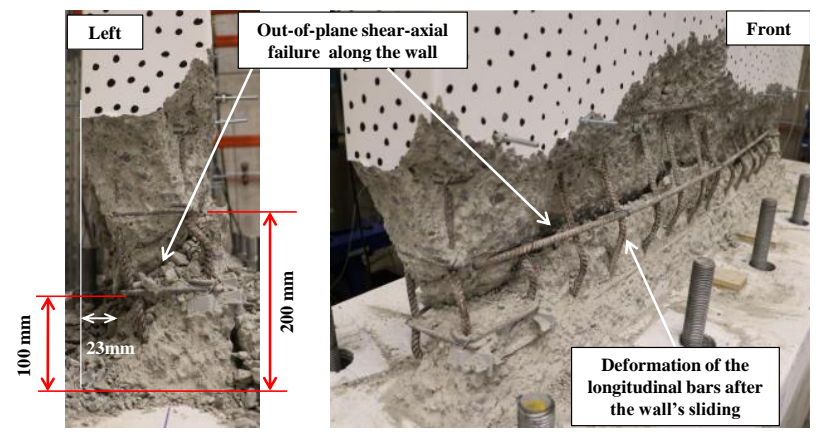

Figure 9: Example of a shear-axial failure [26].

Based on the numerical and experimental investigations conducted by Niroomandi et al. [26, 27] the curve shown in Figure 10 was developed to explain the influence of axial load ratio and cross-sectional aspect ratio on the bi-directional shearaxial failure described above. The curve shown in Figure 10 was developed for walls with section detailing of nominal ductility class or lower, slender walls with an in-plane shear span ratio of 3.5, low longitudinal reinforcement ratio $(0.45 \%$ for Grade 300 reinforcement), and out-of-plane shear span ratio 
of 5 (defined as half the first floor height to wall thickness ratio). Figure 10 shows that, for a given wall geometry and reinforcement detailing, increasing the axial load ratio above $10 \%$ increases the possibility of developing a premature through-the-thickness shear-axial failure mode. This trend continues to a certain point beyond which the failure mode will change to an axial compression (crushing) failure. Although the graph shown in Figure 10 was developed for walls with low longitudinal reinforcement ratio, it is likely (based on the experiment and numerical investigations [26]) that walls with higher longitudinal reinforcement ratio will follow the same trends.

Key recommendation: To address the higher potential for through-the-thickness shear-axial failure, for rectangular walls subject to bi-directional loading with section aspect ratio smaller than 12 and axial loads above $0.1 \mathrm{Agf}^{\prime}$ c, the wall section should be designed in accordance to ductile or limited ductile wall detailing provisions (i.e., confinement of the full neutral axis length and cross-ties on longitudinal web reinforcement), as required by NZS 3101 .

Future research: Research is necessary to provide a methodology for estimating the anticipated magnitude of bidirectional demands in prototype walls buildings. Subsequently, it is necessary to assess the validity of $\mathrm{K}_{\mathrm{d}}$ limits recommended in Table 6 over a range of bi-directional demands.

Future research: Potential limitation on design axial load and other critical parameters should be considered to address the observed reduction in drift capacity for rectangular walls subjected to bi-directional loading and the development of a through-the-thickness failure.

Future research: The effects of bi-directional loading on wall performance should be considered in the context of flanged walls.

\section{Out-of-Plane Wall Instability}

A numerical modelling approach based on the curved shell finite element was proposed to predict out-of-plane instability of rectangular structural walls under pure in-plane loading. The modelling approach was comprehensively validated against results of several tested wall specimens $[13,15,39]$ and was used to investigate the effects of different parameters on development of this mode of failure in doubly reinforced rectangular walls [18].

An experimental campaign was conducted to investigate the effect of slenderness (unsupported height-to-thickness) ratio, length, axial load and longitudinal reinforcement ratio of the boundary regions on the out-of-plane failure mechanism of rectangular walls $[14,18,41]$. The progression and recovery of out-of-plane deformation and evolution of the subsequent instability observed in the wall experiments was in agreement with the numerical model predictions and with the theoretical description of the out-of-plane section buckling mechanism by Paulay and Priestley [49] and Chai and Elayer [50].

The out-of-plane response of walls was found to have four Stages: (i) minimal or no, (ii) fully recoverable, (iii) partially recoverable and (iv) irrecoverable out-of-plane deformation. The magnitude of tensile strain in longitudinal reinforcement in previous cycles was identified to be the factor governing the development of these stages. Figure 11 shows the evolution and recovery of out-of-plane deformation (Stage ii) predicted by the numerical model. Stages iii and iv were found to be in correlation with the stability criterion and upper bound limits proposed by Paulay and Priestley [49], respectively. Figure 12 indicates development of these stages in one of the wall specimens tested by Dashti et al. [41]. Stage iv would result in abrupt strength degradation of the wall and possibly collapse of the structure. Therefore, the stability criterion used in the existing analytical models to limit the tensile strain of the longitudinal bars (and adopted in NZS 3101:2006) was identified to be a reliable criterion for definition of the critical strain prior to global instability. The assumption of buckling length up the height of the wall controls the minimum thickness criteria in the analytical model of Paulay and Priestley [49]. Paulay and Priestley previously assumed a buckled length equal to the length of the plastic hinge, whereas testing by Dashti et al. [41] and several others [51, 52] has shown that the buckled length can exceed the plastic hinge length by more than a factor of two. The buckling length may be better quantified by a fraction of the unsupported wall height, with ratios of 0.7-0.75 observed in testing $[41,51,52]$, though the type of restraint at the storeys will affect this value.
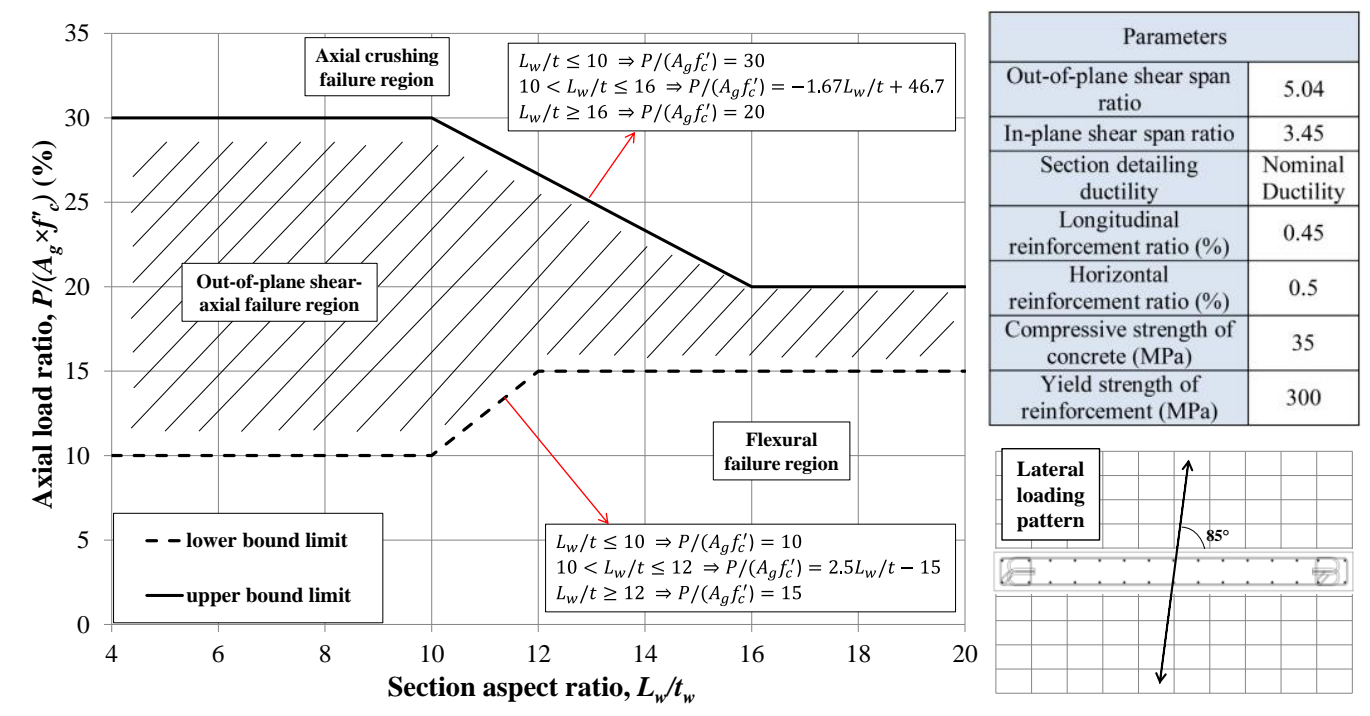

Figure 10: Effect of axial load ratio and section aspect ratio on the failure mode of rectangular slender walls subjected to bidirectional loading [26]. 

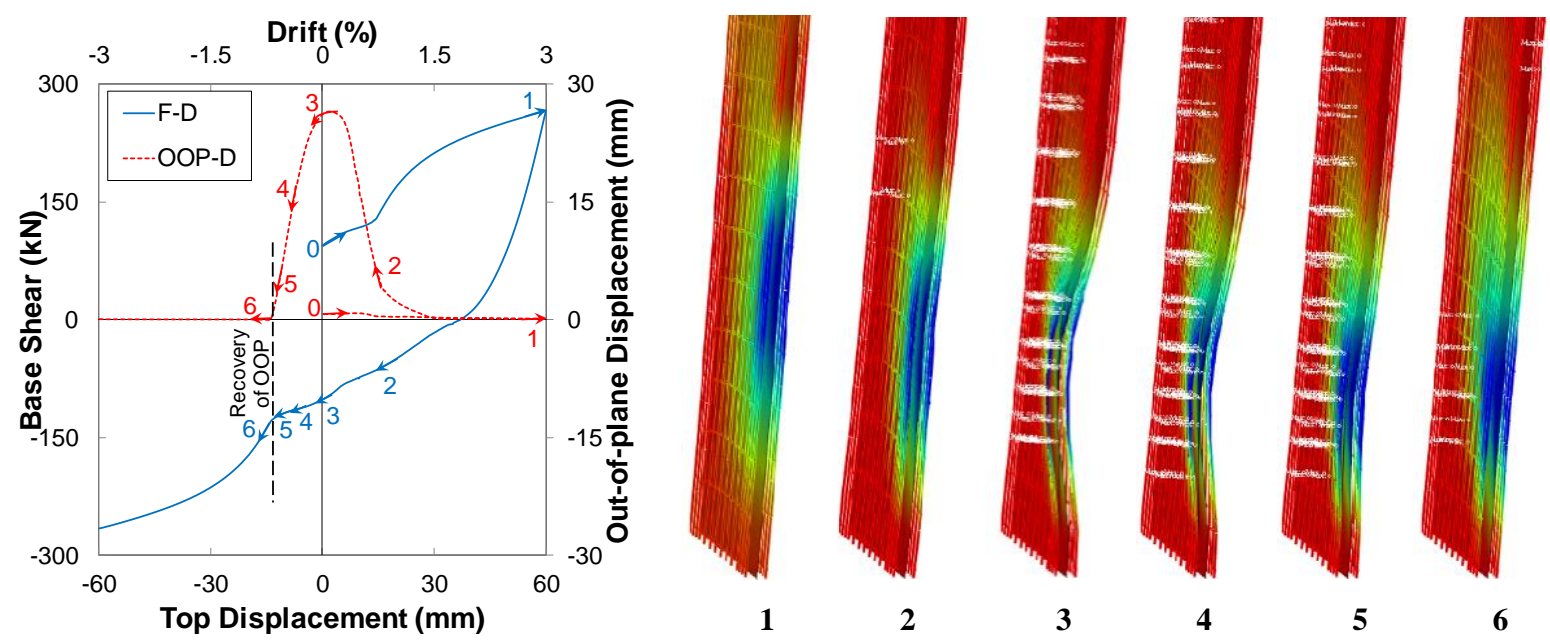

Figure 11: The progression and recovery of out-of-plane deformation simulated by curved shell finite element model [39].

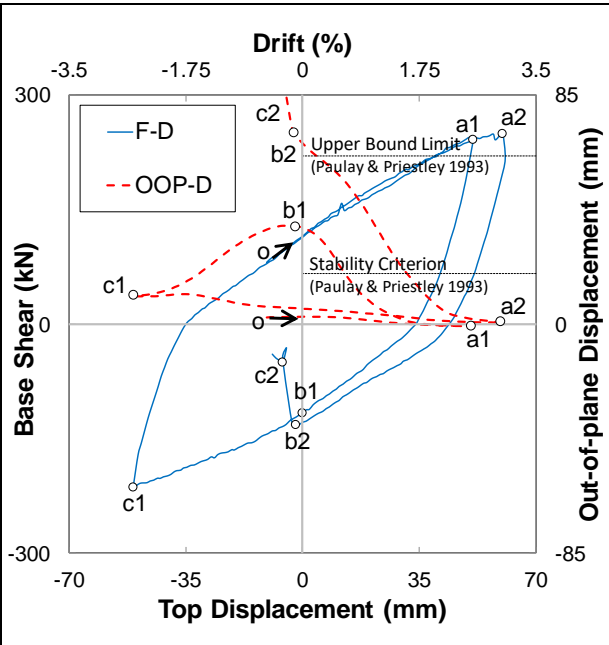

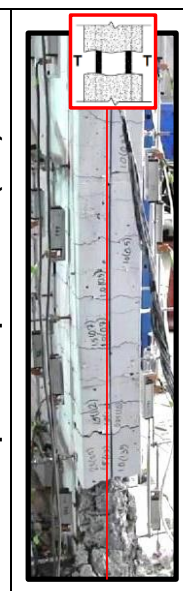

(a1)

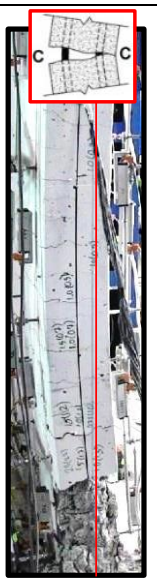

(b1)

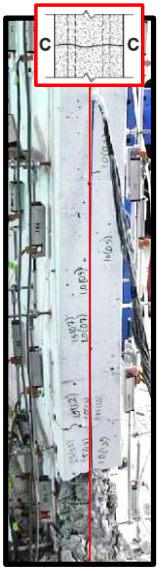

(c1)

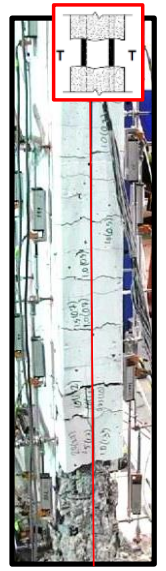

(a2)

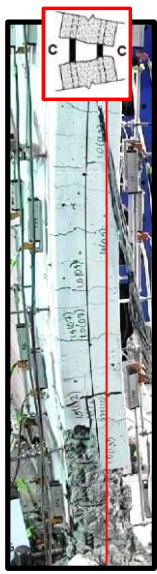

(b2)

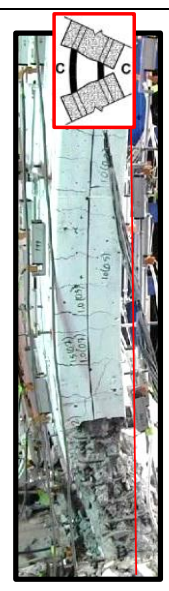

(c2)

Figure 12: Evolution of out-of-plane deformation and subsequent global instability - experimental observation [41].

Based on these experimental observations and the modes of instability failure documented in the literature, the out-of-plane response of walls is classified into five different modes [21]. The global out-of-plane instability (Figure 12) is the only mode that results in abrupt strength degradation of the wall and is associated with development of large strains along a sufficient height of the wall from the base. Therefore, aside from the magnitude of the tensile strain in the longitudinal reinforcement, the distribution of tensile strain along the wall height was also found to be a critical parameter in the evolution of out-of-plane deformation. Thus, doubly-reinforced rectangular walls with well-confined boundary regions and high longitudinal and horizontal reinforcement ratios are susceptible to the abrupt global out-of-plane instability failure if they are able to develop large tensile strains along the height of the plastic region before progression of other failure modes (such as bar buckling, bar fracture and concrete crushing) and before progression of large diagonal cracks along the web. If other failure modes occurred earlier, they can interact with development and recovery of out-of-plane deformation and result in a more localized instability that can be classified as a secondary mode of failure. The failure mode observed in several highly reinforced and well-confined walls during the 2010 Chile and 2010/2011 Canterbury earthquakes exhibited the specific characteristics of the global instability [21].
Based on the numerical and experimental parametric studies $[17,18]$, the controlling parameters were classified into: (i) slenderness (unsupported height-to-thickness) ratio; (ii) the parameters that govern the vertical strain history and vertical strain gradients (e.g. axial load, wall length, longitudinal reinforcement ratio, concrete strength, loading history) and (iii) out-of-plane boundary conditions and different sources of eccentricity. As the main factor controlling the development of this mode of failure is the previously generated tensile strain in the boundary regions of walls, lower slenderness would be required if the progression of out-of-plane instability was to be prevented up to a higher drift level. Therefore, design equations should restrict wall slenderness based on the maximum expected drift demand and give consideration to the boundary zone longitudinal reinforcement ratio and the length-tounsupported height ratio given their influences were found to be more prominent. Since the axial load ratio was found to have a mixed effect on the development of out-of-plane wall instability $[15,18]$, the design provisions to avoid this mode of failure cannot be restricted to a specific range of axial load ratios [22]. Observation of global out-of-plane instability in Specimen R2 tested by Oesterle et al. [53], which was not subjected to any axial load, is a good case in point.

The current provisions of the New Zealand concrete design standard limit the thickness (not the slenderness) and therefore ignore the key effect of the unsupported height. Also, the 
buckling length, assumed to be equal to the theoretical length of the plastic hinge, is incorporated to put a limitation on the resultant thickness for cases with large length-to-unsupported height ratios (while experimental and numerical studies have shown that the buckled length can exceed the plastic hinge length by more than a factor of two). Furthermore, the New Zealand requirements related to instability failure of structural walls are applicable to the axial load ratios greater than $0.05 A_{g} f_{c}^{\prime}$ whereas this mode of failure can occur under lower (and even zero) axial load ratios.

Key recommendation: As singly reinforced walls are more susceptible to the global out-of-plane instability than doubly reinforced walls, restricting their application in design to nominally ductile structures, as required by NZS 3101, is justified.

Key recommendation: Among the measures that could be used to reduce the probability of out-of-plane instability in rectangular walls, increasing the wall thickness, i.e. decreasing the slenderness (height-to-thickness ratio) and length-tothickness ratios, is the most efficient approach. If a change in thickness is not feasible, the likelihood of out-of-plane deformation can be more efficiently reduced by using multiple shorter walls rather than increasing the reinforcement ratio in a single wall. Alternatively, the use of barbell-shaped wall sections with boundary elements thicker than the wall web will obviate the need to consider out-of-plane instability as a potential failure mode.

Key recommendation: The current stability criterion adopted in NZS 3101:2006 (based on Paulay and Priestley [49]) is a reliable criterion for formation of residual out-of-plane deformation. Therefore, the tensile strain that results in progression of this stability criterion during loading reversal is a reliable limit state for development of design equations that prevent global instability.

Key recommendation: The current provisions of the New Zealand concrete design standard to prevent this mode of failure (Cl 11.4.3.2, NZS 3101:2006-A3) limit the thickness (not the slenderness), therefore ignoring the key effect of the unsupported height. Also, the buckling length, used to limit the wall thickness for cases with large length-to-unsupported height ratios is assumed to be equal to the theoretical length of the plastic hinge whereas experimental and numerical studies have shown that this length can exceed the plastic hinge length by more than a factor of two. The NZS 3101 provisions should therefore be revised to consider these points.

Key recommendation: Provisions for minimum thickness criteria for wall instability in NZS 3101:2006-A3 (Cl 11.4.3.2) should be extended to apply to walls with axial load ratios below $5 \%$.

Future research: The critical tensile strain that results in outof-plane displacement larger than the stability criterion should be determined through a parametric study using a verified numerical model. Design equations should be developed based on this strain limit to restrict wall geometry based on the maximum expected drift demand.

\section{KEY FINDINGS RELEVANT TO EXISTING BUILDINGS}

Selected research within the MBIE wall research program has also targeted recommendations for the assessment of existing building structures. These recommendations are primarily focused on improving the New Zealand Seismic Assessment Guideline for Existing Buildings [10]. Key findings from the
MBIE wall projects that are relevant for assessment of walls in existing buildings are summarised below. The status of the recommendations for adoption in the NZ Seismic Assessment Guideline is also given.

\section{Axial Failure Model for Cast in-situ Singly Reinforced Walls}

Testing of four cast in-situ singly reinforced RC walls under inplane, cyclic, pseudo-static loading showed that wall response was controlled by a few large dominant cracks [35] at the base of the wall. Lateral wall failure occurred due to fracture of longitudinal reinforcement. For singly reinforced walls tested with axial load ratios of $10 \%$, lateral load failure was rapidly followed by axial crushing along a diagonal failure plane spanning the entire length of the wall (through-the-thickness failure) [35]. This type of failure is classified as a 'severe structural weakness' in the NZ Seismic Assessment Guideline [10] as it is linked to potential for catastrophic collapse of the structure. Data from these tests as well as from existing tests of nominally ductile walls, were graphed in Figure 13 against axial load ratio and transverse reinforcement spacing to wall thickness ratio $\left(\mathrm{s} / \mathrm{t}_{\mathrm{w}}\right)$. By identifying the failure mode for each wall, a boundary (shown as a dot-dashed line in Figure 13) was delineated to separate walls prone to through-the-thickness failure [23] from flexural failures. Criteria for this boundary were developed and are summarised in Equations (3)-(4).

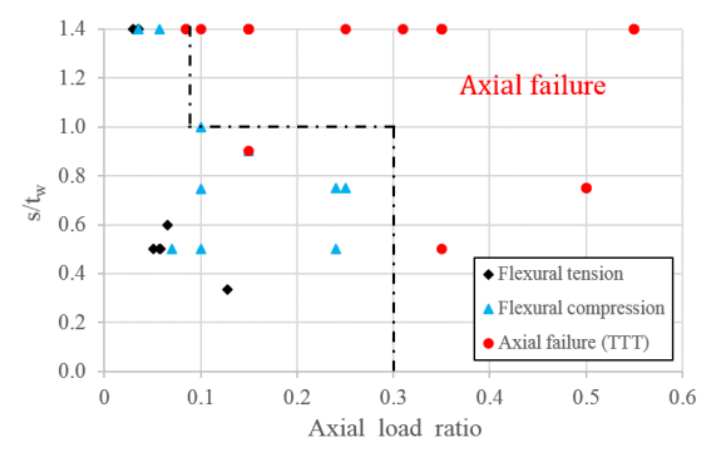

Figure 13: Axial failure model for singly reinforced walls.

$$
\frac{\left(A_{s}-A_{s}^{\prime}\right) f_{y}+P^{*}}{t_{w} L_{w} f_{c}^{\prime}}>0.3
$$

OR

$$
\mathrm{s} / t_{w}>1 \quad \text { and } \quad \frac{\left(A_{s}-A_{s}^{\prime}\right) f_{y}+N^{*}}{t_{w} L_{w} f_{c}^{\prime}}>0.08
$$

where $A_{s}$ and $A_{S}^{\prime}=$ areas of tension and compression longitudinal reinforcement in the wall, respectively, as determined by the position of the neutral axis length when the critical concrete compression fiber reaches a strain of 0.004 ;

$f_{y}=$ probable yield stress of longitudinal reinforcement;

$P^{*}=$ applied axial load;

$f_{c}^{\prime}=$ probable concrete compressive stress;

$t_{w}=$ wall thickness;

$L_{w}=$ wall length; and

$s=$ vertical hoop/tie spacing in the wall end region.

Key recommendation: It is recommended that criteria in Equations (3)-(4) are used to determine if axial through-thethickness failure is likely to govern the failure of existing singly reinforced rectangular walls. These criteria have been adopted in the Technical Proposal to Revise the Engineering Assessment Guidelines [54]. 


\section{Deformation Capacity Limits for Cast in-situ Walls}

\section{Ductile Walls}

Typically, deformation capacity limits for assessment of existing buildings should provide a probable estimate of deformation capacity and should therefore exceed deformation demand limits for new design (which are a lower-bound, conservative estimate). A comparison of existing deformation capacity limits specified in the NZ Seismic Assessment Guideline with a set of ductile wall test data is shown in Figure 14a. It can be seen that the existing probable deformation capacity limit is conservative with respect to experimental data. The proposed deformation capacity assessment limit is derived using the model developed in Equation (2) with a set of alternative strain limits recommended in Table 6 . The proposed deformation capacity limit is plotted in Figure 14a and it can be seen that it is more representative of deformation capacity observed in experimental data. Using Equation (2) to define probable deformation capacity limits also ensures that the wall assessment procedure is consistent with the NZS 3101 wall design procedure proposed earlier in the paper.

Key recommendation: Consistent with the design demand limits proposed in the 'Design of Ductile Walls' section of this paper, it is recommended that probable deformation capacity limit for RC walls is described using Equation (2) with

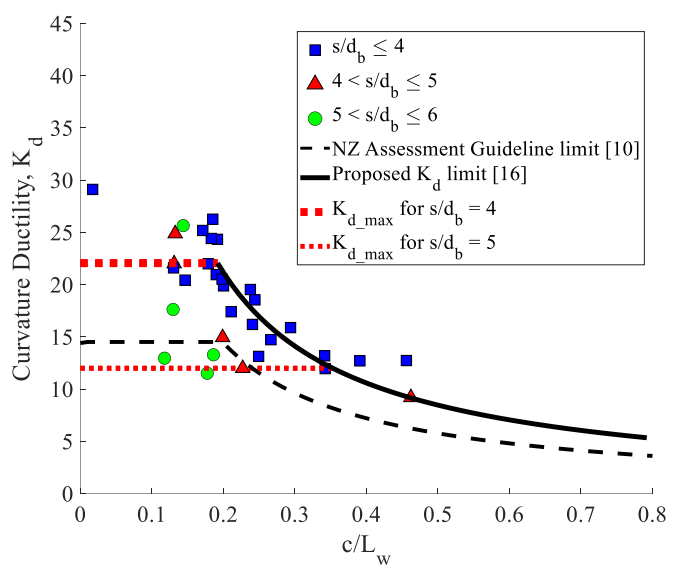

(a) reference to Table 6 . This recommendation has been adopted in the Technical Proposal to Revise the Engineering Assessment Guidelines [54].

\section{Nominally/Limited Ductile Walls}

A database of walls detailed to nominally/limited ductile wall provisions was assembled by Crowe [55] and Shegay et al. [16]. As in Figure 14a for ductile walls, similar curvature ductility capacity trends are observed with respect to $c / L_{w}$ for the nominally/limited ductile walls, as seen in Figure 14b. Shegay et al. [16] extended the model presented in Equation (2) to apply for assessment of nominally/limited ductile walls, with recommended corresponding strain limits shown in Table 6 . Figure 14b shows that the Shegay et al. model can be further simplified by a linear function (Equation(5)) that provides a good estimate of the probable curvature ductility capacity [55].

$$
K_{d}=15-20 c / L_{w}
$$

Key recommendation: It is recommended that Equation (5) by Crowe [55] or Equation (2) by Shegay et al. [16] (with reference to Table 6) are used for the assessment of probable curvature ductility capacity of nominally/limited ductile walls. Equation (5) has been incorporated into the Technical Proposal to Revise the Engineering Assessment Guidelines [54].

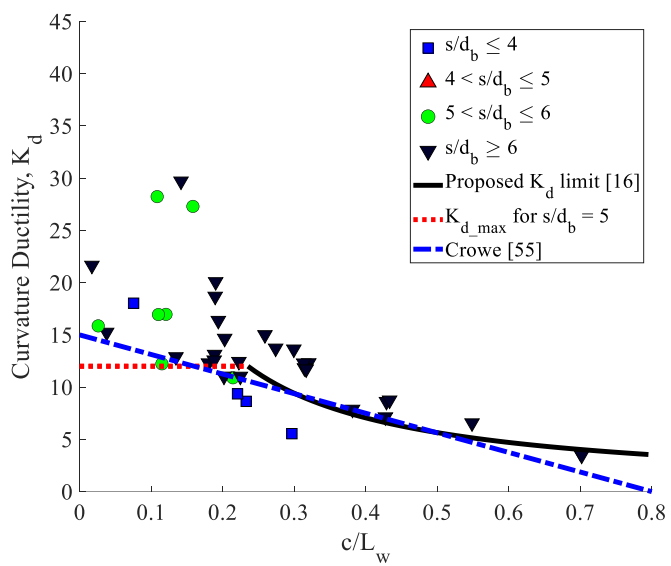

(b)

Figure 14: Comparison of experimental curvature ductility capacity with proposed probable capacity assessment limits for NZ Assessment Guidelines for (a) ductile walls and (b) nominally/limited ductile walls.

\section{CONCLUSIONS}

Following observations of $\mathrm{RC}$ wall performance in the 2010/2011 Canterbury earthquakes, a four-year RC wall research programme was funded by the Building Performance Branch of the New Zealand Ministry of Business, Innovation and Employment. The research was targeted at advancing the understanding of behaviour of (i) lightly reinforced walls, including precast connections, (ii) ductile walls, (iii) walls subjected to bi-directional loading and (iv) out-of-plane global instability of walls. These projects were undertaken collaboratively by the University of Auckland and the University of Canterbury, each resulting in improved understanding on the seismic performance of walls and producing several recommendations for the design of new and assessment of existing reinforced concrete wall buildings. Some of these recommendations have already been implemented into the New Zealand Concrete Structures Standard (NZS 3101:2006-A3) and the Technical Proposal to Revise the Engineering Assessment Guidelines.
The lightly reinforced wall project produced recommendations relating to minimum vertical reinforcement ratio requirements in walls to ensure ductility is appropriately distributed over the plastic hinge length. Recommendations on minimum vertical reinforcement have already been adopted in NZS 3101:2006A3. Experimental work on precast wall-to-foundation connections highlighted the inadequacies of common connection details and provided recommendations for improved alternative detailing. The ductile wall project culminated in a deformation capacity model which was then used to develop deformation demand and capacity limits for design and assessment of RC walls, respectively. Research into bi-directional loading on $\mathrm{RC}$ walls demonstrated that out-ofplane demands can accelerate damage progression and failure of walls. Additionally, wall characteristics that resulted in highest vulnerability of walls to premature axial failure from bidirectional loading demands were identified. Finally, research into out-of-plane global instability of walls verified the mechanics behind this failure mode and identified shortcomings in the buckling length assumptions used to develop current stability criteria in NZS 3101:2006-A3. 


\section{ACKNOWLEDGEMENTS}

The authors would like to acknowledge the Building Systems Performance branch of the New Zealand Ministry of Business, Innovation and Employment for providing the funding which enabled the multiple research projects described in this paper to be undertaken. Thanks are also extended to UC Quake Centre for managing the contracts of each of the projects. The authors would also like to acknowledge the support provided from industry (including Fletcher Reinforcing, Allied Concrete, Wilco Precast, Stresscrete and Reids ITW) and research institutions (MAST laboratory at Swinburne University and QuakeCoRE), in form of professional advice, construction materials and testing equipment. Finally, many thanks are expressed to the group of students and researchers that have undertaken the research in each project, including Prof. Jason Ingham, Dr. Christopher Motter, James Burely, Sophie Burridge, Mark Casey, Signy Crowe, Tautua Faitotoa, Morgan Raby and Hayden Wright.

\section{REFERENCES}

1 Sritharan S, Beyer K, Henry RS, Chai YH, Kowalsky M and Bull D (2014). "Understanding poor seismic performance of concrete walls and design implications". Earthquake Spectra, 30(1): 307-334.

2 Kam WY, Pampanin S and Elwood K (2011). "Seismic performance of reinforced concrete buildings in the 22 February Christchurch (Lyttelton) earthquake". Bulletin of the New Zealand National Society for Earthquake Engineering, 44(4): 239-278.

3 Elwood KJ (2013). "Performance of concrete buildings in the 22 February 2011 Christchurch earthquake and implications for Canadian codes". Canadian Journal of Civil Engineering, 40(8): 759-776.

4 Canterbury Earthquakes Royal Commission (CERC) (2012). "Volume 2: The Performance of Christchurch CBD Buildings". Canterbury Earthquakes Royal Commission, Ministry of Building, Innovation and Employment. Wellington, New Zealand.

5 Standards Association of New Zealand (1982). "NZS 3101:1982: Part 1: Code of Practice for the Design of Concrete Structures". Standards New Zealand, Wellington, New Zealand.

6 Standards New Zealand (1999). "NZS 3101:1995: Concrete Structures Standard Part 1- The Design of Concrete Structures (Amendment No. 2)". Standards New Zealand, Wellington, New Zealand.

7 Standards New Zealand (2008). "NZS 3101:2006: Concrete Structures Standard Part 1 - The Design of Concrete Structures (Amendment No. 2)". Standards New Zealand, Wellington, New Zealand.

8 Structural Engineering Society New Zealand (SESOC) (2013). "Interim Design Guidance: Design of Conventional Structural Systems Following the Canterbury Earthquakes". Wellington, New Zealand.

9 Canterbury Earthquakes Royal Commission (CERC) (2012). "Volume 1: Summary and Recommendations in Volumes 1-3. Seismicity, Soils and the Seismic Design of Buildings". Canterbury Earthquakes Royal Commission. Ministry of Building, Innovation and Employment. Wellington, New Zealand.

10 New Zealand Society for Earthquake Engineering (NZSEE) (2017). "The Seismic Assessment of Existing Buildings: Technical Guidelines for Engineering Assessment. Part C5 Concrete Buildings". Joint Publication of NZSEE, SESOC, NZGS, MBIE, and EQC, Wellington, New Zealand.

11 Shegay AV, Motter CJ, Elwood KJ, Henry RS, Lehman DE and Lowes LN (2018). "Impact of axial load on the seismic response of rectangular walls". Journal of Structural Engineering, 144(8): 1-32.

12 Shegay AV (2019). "Seismic Performance of Reinforced Concrete Walls Designed For Ductility". PhD Thesis, University of Auckland.

13 Dashti F, Dhakal RP and Pampanin S (2018). "Blind prediction of in-plane and out-of-plane responses for a thin singly reinforced concrete flanged wall specimen". Bulletin of Earthquake Engineering, 16(1): 427-458.

14 Dashti F, Dhakal RP and Pampanin S (2017). "Tests on slender ductile structural walls designed according to New Zealand Standard". Bulletin of the New Zealand Society for Earthquake Engineering, 50(4): 504-516.

15 Dashti F, Dhakal RP and Pampanin S (2018). "Validation of a numerical model for prediction of out-of-plane instability in ductile structural walls under concentric in-plane cyclic loading". Journal of Structural Engineering, 144(6): 040180391-04018039-22.

16 Shegay AV, Motter CJ, Elwood KJ and Henry RS (2019). "Deformation capacity limits for reinforced concrete walls". Earthquake Spectra, 35(3): 1189-1212.

17 Dashti F, Tripathi M, Dhakal RP and Pampanin S (2020). "A parametric study on out-of-plane instability of doubly reinforced structural walls. Part II: Experimental investigation". Bulletin of Earthquake Engineering (Accepted for Publication).

18 Dashti F, Dhakal RP, and Pampanin S (2020). "A parametric study on out-of-plane instability of doubly reinforced structural walls. Part I: FEM predictions". Bulletin of Earthquake Engineering, https://doi.org/10.1007/s10518-020-00828-w.

19 Dashti F, Dhakal RP and Pampanin S (2019). "A parametric investigation on applicability of the curved shell finite element model to nonlinear response prediction of planar RC walls". Bulletin of Earthquake Engineering, 17(12): 6515-6546.

20 Dashti F, Dhakal RP and Pampanin S (2018). "Local vs global instability of ductile structural walls". New Zealand Conference on Earthquke Engineering, 13-15 April, Auckland, New Zealand.

21 Dashti F, Dhakal RP and Pampanin S (2020). "Out-of-plane response of in-plane-loaded ductile structural walls: State-ofthe-art and classification of the observed mechanisms". Journal of Earthquake Engineering, DOI: 10.1080/13632469.2020. 1713928.

22 Dashti F, Dhakal RP and Pampanin S (2017). "Evaluation of New Zealand code requirements related to instability failure of structural walls". New Zealand Conference on Earthquake Engineering, 27-29 April, Wellington, New Zealand.

23 Shegay AV, Zhang T, Elwood KJ and Henry RS (2018). "Deformation capacity of concrete walls: research findings for both old and new design practice". The Concrete NZ Conference, 11-13 October, Hamilton, New Zealand.

24 Dashti F, Dhakal RP and Pampanin S (2014). "Simulation of out-of-plane instability in rectangular RC structural walls". Second European Conference on Earthquake Engineering and Seismology, 25-29 August, Istanbul, Turkey, p. 13.

25 Niroomandi A, Pampanin S, Dhakal RP and Ashtiani MS (2018). "Experimental study on slender rectangular RC walls under bi-directional loading". Eleventh U.S. National Conference on Earthquake Engineering, 25-29 June, 2018, Los Angeles, California.

26 Niroomandi A (2018). "Seismic Behaviour of Rectangular Reinforced Concrete Walls under Bi-Directional Loading". $\mathrm{PhD}$ Thesis, University of Canterbury.

27 Niroomandi A, Pampanin S, Dhakal RP, Ashtiani MS and De La Torre C (2018). "Rectangular RC walls under bi-directional loading: recent experimental and numerical findings". The Concrete NZ Conference 2018, 11-13 October, Hamilton, New Zealand. 
$28 \mathrm{Lu} \mathrm{Y}$ and Henry RS (2016). "Numerical modelling of reinforced concrete walls with minimum vertical reinforcement". Engineering Structures, 143: 1689-1699.

29 Niroomandi A, Ashtiani MS, Pampanin S and Dhakal RP (2017). "Numerical investigations on rectangular squat renforced concrete walls under bi-directional loading". Proceedings of the 16th World Conference on Earthquake Engineering, 6-13 January, 2017, Santiago, Chile.

$30 \mathrm{Lu} \mathrm{Y}$ and Henry RS (2018). "Comparison of minimum vertical reinforcement requirements for reinforced concrete walls". ACI Structural Journal, 115(3): 673-687.

31 Lu Y (2017). "Seismic Design of Lightly Reinforced Concrete Walls", PhD Thesis, University of Auckland.

32 Lu Y, Gultom RJ, Ma QQ and Henry RS (2018). "Experimental validation of minimum vertical reinforcement requirements for ductile concrete walls". ACI Structural Journal, 115(4): 11151130.

$33 \mathrm{Lu} \mathrm{Y}$ and Henry RS (2017). "Minimum vertical reinforcement in RC walls: theoretical requirements for low and high ductility demands". Bulletin of the New Zealand Society for Earthquake Engineering, 50(4): 471-481.

34 Hogan L, Henry RS and Ingham MJ (2018). "Performance of panel-to-foundation connections in low-rise precast concrete buildings". Journal of the Structural Engineering Society of New Zealand Inc, 31(1): 26-36.

35 Zhang T, Elwood KJ and Henry RS (2018). "Testing of singly reinforced concrete walls used in existing buildings". Proceedings of New Zealand Society for Earthquake Engineering Conference 2018, 12-15 April, 2018, Auckland, New Zealand, pp. 1-8.

36 Seifi P, Henry RS and Ingham JM (2019). "In-plane cyclic testing of precast concrete wall panels with grouted metal duct base connections". Engineering Structures, 184: 85-98.

37 Seifi P, Henry RS and Ingham JM (2017). "In-plane testing of precast concrete wall panels with grouted sleeve". Proceedings of New Zealand Society for Earthquake Engineering Conference, Wellington, New Zealand.

38 Lu Y, Henry RS, Gultom R and Ma QT (2017). "Cyclic testing of reinforced concrete walls with distributed minimum vertical reinforcement". Journal of Structural Engineering, 143(5): 04016225-1-04016225-17.

39 Dashti F, Dhakal RP and Pampanin S (2017). "Numerical modeling of rectangular reinforced concrete structural walls". Journal of Structural Engineering, 143(6): 1-14.

40 Dashti F (2017). "Out-of-Plane Instability of Rectangular Reinforced Concrete Walls Under in-Plane Loading". PhD Thesis, University of Canterbury, Christchurch, New Zealand.

41 Dashti F, Dhakal RP and Pampanin S (2018). "Evolution of outof-plane deformation and subsequent instability in rectangular RC walls under in-plane cyclic loading: Experimental observation". Earthquake Engineering and Structural Dynamics, 47(15): 2944-2964.
42 Wilson A and Lewis C (2011). "Novotel Cathedral Square: Structural Damage Report following 22/02/11 Earthquake and Subsequent Aftershocks". Lewis Bradford Consulting Engineers. Project No. 110170.

43 Pampanin S, Weng KY, Akguzel U, Tasligedik AS and Quintana-Gallo P (2012). "Seismic Performance of Reinforced Concrete Buildings in the Christchurch Central Business District in 22 February 2011 Earthquake. Part II : Damage Observation". National Hazards Research Platform Report, 629pp.

44 Pampanin S, Weng KY, Akguzel U, Tasligedik AS and Quintana-Gallo P (2012). "Seismic Performance of Reinforced Concrete Buildings in the Christchurch Central Business District. Part I: Overview". National Hazards Research Platform Report, 104pp.

45 Beca Carter Hollings \& Ferner Ltd (2011). "Investigation into the Collapse of the Pyne Gould Corporation Building on 22nd February 2011". Report for the Department of Building and Housing, 46pp.

46 Standards New Zealand (2017). "NZS 3101:2006: Concrete Structures Standard Part 1- The Design of Concrete Structures (Amendment No. 3)". Standards New Zealand, Wellington, New Zealand.

47 Deng M, Liang X and Zhang S (2009). "Experimental study on ductility of high performance concrete shear walls". Journal of Building Structures, (S1): 139-143.

48 Whitman ZJ (2015). "Investigation of Seismic Failure Modes in Flexural Concrete Walls Using Finite Element Analysis". MSc Thesis, University of Washington.

49 Paulay T and Priestley MJN (1993). "Stability of ductile structural walls". ACI Structural Journal, 90(4): 385-392.

50 Chai YH and Elayer DT (1999). "Lateral stability of reinforced concrete columns under axial reversed cyclic tension and compression". ACI Structural Journal, 95(5): 780-789.

51 Rosso A, Almeida J and Beyer K (2016). "Stability of thin reinforced cocnrete walls under cyclic loads: state-of-the-art and new experimental findings". Bulletin of Earthquake Engineering, 14(2): 455-484.

52 Johnson BM (2010). "Anchorage Detailing Effects on Lateral Deformation Components of $R / C$ Shear Walls". ME Thesis, University of Minnesota.

53 Oesterle RG, Fiorato AE, Johal LS, Carpenter JE, Russell HG and Corley WG (1976). "Earthquake Resistant Structural Walls - Tests of Isolated Walls". Washington D.C.: PCA-R/D-SER1571, National Science Foundation.

54 New Zealand Society for Earthquake Engineering (NZSEE) (2018). "Technical Proposal to Revise the Engineering Assessment Guidelines". NZSEE.

55 Crowe SE (2018). "Seismic Performance of Older Reinforced Concrete Walls". ME Thesis, University of Auckland. 